\title{
Comparison of Inundation Depth and Momentum Flux based Fragilities for Probabilistic Tsunami Damage Assessment and Uncertainty Analysis.
}

Hyoungsu Park*, Postdoctorate Scholar, School of Civil and Construction Engineering, Oregon State University, Corvallis, OR 97331-2302, USA, Email: Hyoungsu.Park@gmail.com, Tel: 1-541-829-0358, Fax: 541-737-3052

Daniel T. Cox, Professor, School of Civil and Construction Engineering, Oregon State University, Corvallis, OR 97331-2302, USA, Email: dan.cox@ oregonstate.edu

Andre R. Barbosa, Assistant Professor, School of Civil and Construction Engineering, Oregon State University, Corvallis, OR 97331-2302, USA, Email: andre.barbosa@oregonstate.edu

* Corresponding Author

\begin{abstract}
Annual exceedance probabilities of the maximum tsunami inundation depth, $h_{\text {Max }}$, and momentum flux, $M_{\text {Max }}$, conditional on a full-rupture event of the Cascadia Subduction Zone (CSZ) were used to estimate the probability of building damage using a fragility analysis at Seaside, Oregon. Tax lot data, Google Street View, and field reconnaissance surveys were used to classify the buildings in Seaside and to correlate building typologies with existing fragility curves according to the construction material, number of stories, and building seismic design level based on the date of construction. A fragility analysis was used to estimate the damage probability of buildings for 500-, 1,000-, and 2,500-year exceedance probabilities conditioned on a full-rupture CSZ event. Finally, the sensitivity of building damage was estimated for both the aleatory and epistemic uncertainties involved in the process of damage estimation. Probable damage estimates from the fragility curves based on $h_{\operatorname{Max}}$ and on $M_{\text {Max }}$ both generally show higher damage probability for structures that are wooden and closer to the shoreline than those that are reinforced concrete (RC) and further landward of the shoreline. However, a relatively high and somewhat unrealistic damage probability was found at the river and creek region from the fragility curve analysis using $h_{\text {Max }}$. Within $500 \mathrm{~m}$ from the shoreline, wood structure damage shows significant sensitivity to the aleatory uncertainty of the tsunami generation from the CSZ event. On the other hand, RC structure damage showed equal sensitivity to the aleatory uncertainty of the tsunami generation as well as the epistemic uncertainties due to the numerical modeling of the tsunami inundation (friction), the building classification (material and date of construction), and the type of fragility curves (depth or momentum flux type curves). Further from the shoreline, the wood structures showed similar aleatory and epistemic uncertainties, qualitatively similar to the RC structure sensitivity closer to the shoreline.
\end{abstract}

Keywords: Tsunami, Cascadia Subduction Zone, Fragility curves, Building damage, Momentum flux, Disaster resilience 


\section{Manuscript for submission COASTAL ENGINEERING}

\section{Introduction}

Over the past two decades, megathrust earthquakes and resulting tsunamis, such as the 2004 Indian Ocean tsunami, the 2010 Chile tsunami, and the 2011 Tohoku tsunami have generated catastrophic casualties and damage to the built and natural environments. Post-disaster surveys of damage to the built environment (Mori et al., 2013; Naito et al., 2013) highlight the need for strategies to increase the resilience of communities to prepare for future tsunami events and to minimize structural damage and losses. For the study of tsunami resilience, it is necessary to understand the hazard, to estimate how the systems in the built environment will respond, and to predict the recovery processes of infrastructure systems such as buildings, transportation networks (bridges and roads, harbors, railways, and airports), water and wastewater networks, energy networks (electric power and fuel) and communication networks (radio, landlines and wireless). Although the five civil infrastructure systems contain multiple interdependencies, building damage assessment is often studied in isolation for evacuation planning to

minimize casualties or estimate the need for sheltering. Moreover, building damages are utilized to estimate direct and indirect economic and social impacts on the community (Dominey-Howes et al, 2010; Wiebe and Cox, 2014). In addition, damage assessment of critical facilities such as hospitals, schools, fire stations, and city halls is important because such facilities play significant roles in community management, rescue, and recovery at the moment of a tsunami strike and after the event (e.g., Raskin and Wang, 2016).

Tsunami damage assessments of buildings can be analyzed using either deterministic or probabilistic approaches. Deterministic approaches typically consider a small number of scenarios and then choose the largest "reasonable" tsunami for analysis. Probabilistic approaches, on the other hand, typically consider a wide range of possible scenarios and the associated annual rates of occurrence of each scenario. Both deterministic and probabilistic approaches deal with uncertainties in several steps of tsunami vulnerability assessment, including the estimation of both the tsunami intensity and the tsunami-induced damage on the community. In the deterministic damage assessment of buildings from tsunami inundation, several attempts have been made to estimate the direct tsunami-induced forces on buildings based on the tsunami inundation depth, velocity, and building shape (e.g. Yeh, 2007; Nistor et al, 2009). FEMA P-646 (2012) describes seven tsunami-induced forces on a building, namely the hydrostatic force, buoyancy force, hydrodynamic force, impulsive force, debris impact force, debris damming force, and uplift force. Although it might be possible to estimate these forces for an individual building to determine the design considerations to enable it to withstand the tsunami inundation, it is difficult to apply these forces on the 


\section{Manuscript for submission COASTAL ENGINEERING}

scale of an entire city comprised of thousands of buildings. In addition, estimation of the capacity of individual structures is an overwhelming task as there are a wide range of possibilities for failure including foundation failure, structural failure of columns or beams, failure of infilled walls, or the sliding and overturning of buildings (Reese et al., 2007; Valencia et al., 2011; Mori et al., 2013; Yeh et al., 2013; Yeh et al., 2014).

Probabilistic damage assessments using a fragility curve analysis have been widely used to estimate damage to buildings and other infrastructure from diverse hazards such as earthquake, flood, hurricane, and tsunami (Whitman, 1997; Hall et al., 2003; Padgett and DesRoches, 2008; Koshimura et al., 2009; Goda and Song, 2016). The fragility curve describes the probability of reaching or exceeding damage levels for a given intensity measure. The damage levels are often described as slight, moderate, extensive, and complete damage. Slight damage is considered as easily reparable and often does not affect the functionality of the building. Complete damage, on the other hand, implies structural failure of buildings, which can no longer provide for life safety to building occupants. For tsunamis, a higher damage state, "collapse or washed away," can also be considered (Suppasri et al., 2013), which is similar to collapse fragility curves derived for other hazards. The intensity measures (IMs) parameterize the hazard and can include peak ground acceleration (PGA) for earthquakes (MRl, HAZUS-MH, 2003), inundation depth for floods (Scawthorn et al., 2006), maximum wind speed for hurricanes (Ellingwood, et al., 2004; van de Lint and Dao, 2009), and maximum inundation depth, flow velocity, or momentum flux for tsunamis (Koshimura et al., 2009; Suppasri et al., 2013; FEMA, 2013). Different fragility curves are required to differentiate building typologies: for example, construction material (e.g. wood, steel, reinforced concrete, etc.), number of stories, and the age of construction. Therefore, it is necessary to construct a large number of fragility curves to apply this type of analysis to a community with possibly hundreds of different structural typologies. Fragility curves can be derived empirically based on field or laboratory observations of known intensity measures and resulting damage, by numerical simulations, or, in some cases, through expert opinion (e.g., FEMA, 2011).

Because of the use of fragility curves for estimating tsunami damage is still relatively new, there are several outstanding questions. First, there is some question about the appropriate intensity measure (IM) to use, particularly whether depth, $h$, or momentum flux, $M$, of the flow is more appropriate. On the one hand, flow depth can be more easily estimated from field surveys after large tsunamis, while it is more difficult to estimate velocity. On the other hand, the actual damage to the building may be due to the fluid forces (momentum flux) arising from the tsunami velocity and its spatial distribution. Second, there is 
also a question about other sources of uncertainty such as the characterization of the building stock. Third, there are questions about the time dependent nature of damage and how the propagation of failure of one building can influence the failure of other buildings either through changes to the flow field or through debris forces from the damaged or destroyed building. While it is difficult to answer all of these questions simultaneously, this paper develops a general framework for the probabilistic tsunami damage assessment (PTDA) on buildings at a community scale (Section 2) using the City of Seaside, Oregon, as a testbed community, and it provides a brief review of the work of Park and Cox (2016; hereafter PC16) to characterize the tsunami hazard exceedance probability. We describe the two different sets of fragility curves (depth and momentum) in Section 3. In Section 4, we summarize the tools and methods used to collect the building information and present results of the building classification. In Section 5, we show the probabilistic tsunami damage estimation for existing buildings. In Section 6, we present the sensitivity of the probability of damage to uncertainties involved in the damage estimation process and quantitatively compare results obtained from the dominating uncertainties. In Section 7, we discuss limitations of our current study and propose several avenues for improvements in future works. Finally, in Section 8 we summarize the main conclusions of this study.

\section{Methodology and Background}

\subsection{Methodology}

Fig. 1 shows the proposed seven-step framework for PTDA on buildings at a community scale. The flow chart is separated into two major parts: (1) Tsunami Hazard Assessment (Steps 1-4), and (2) Tsunami Damage Assessment (Steps 5-7). The seven steps are as follows:

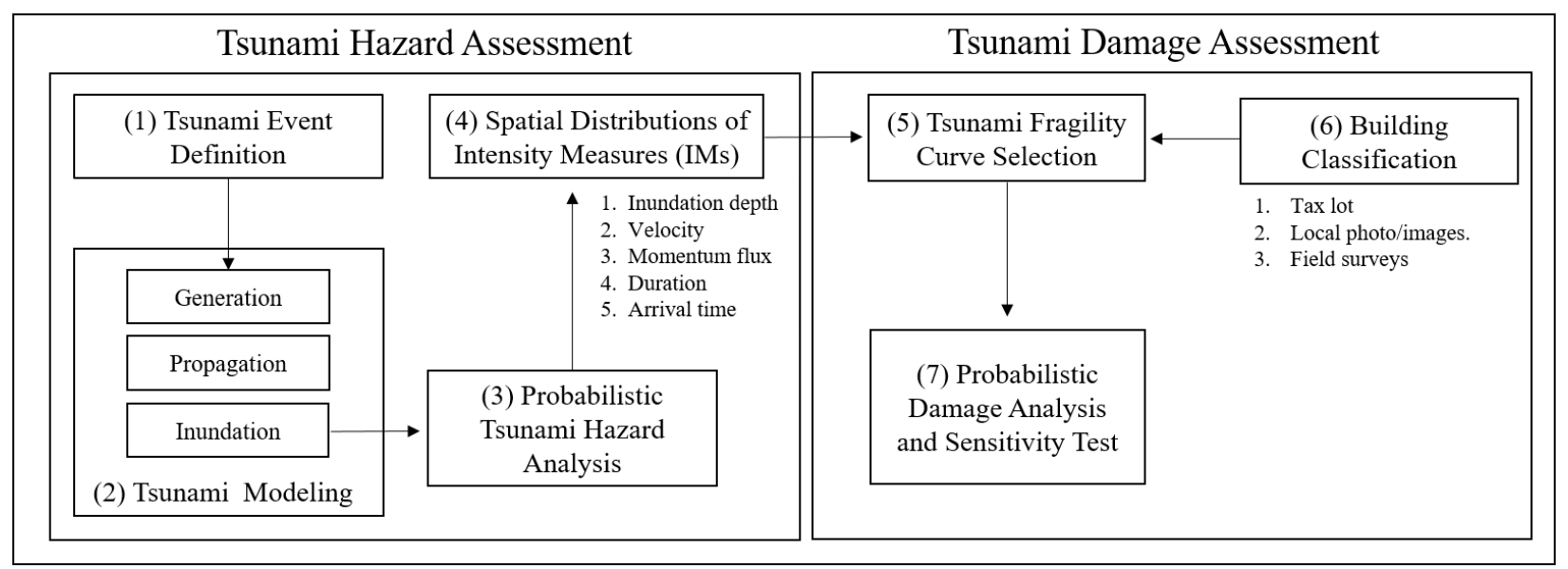




\section{Manuscript for submission COASTAL ENGINEERING}

Fig. 1. Flow chart of the probabilistic tsunami damage assessment (PTDA) process.

Step 1: Tsunami Event Definition. In this step, the seismic conditions are determined. In this paper, the analysis is conditional on a full-rupture CSZ event. Parameters that are needed in the definition of this step include moment magnitude, peak slip location, and slip distribution.

Step 2: Tsunami Modeling. This step includes the modeling of the tsunami generation, propagation, and inundation processes. For this study, the ComMIT/MOST (Titov et al., 2011) model was used for tsunami generation and propagation, and the COULWAVE model (Lynett et al., 2002) was utilized to model tsunami inundation. The COULWAVE model provided the time series of tsunami water surface elevation and velocity over the entire inundation area.

Step 3: Probabilistic Tsunami Hazard Analysis (PTHA). The modeled events are combined using a weighting to account for the likelihood of the events, and a Poisson arrival process (Cornell, 1964) is used to estimate the annual exceedance probability $(P)$ of five intensity measures (IMs), conditional on a full-rupture CSZ event.

Step 4: Spatial Distribution of Intensity Measures (IMs). The spatial distributions of the two of the IMs (maximum inundation depth and maximum momentum flux) are developed for a 0.002 and 0.001 annual exceedance probability (P), which correspond to the return periods such as "500-year" and "1,000-year" events, respectively, based on the assumed Poisson distribution.

Step 5: Tsunami Fragility Curve Selection. For this step, it is necessary to select the appropriate tsunami fragility curves. For this manuscript, the building damage is estimated using existing fragility curves developed for a given set of building characteristics (material, floors, or build year) and the two IMs for which the spatial distribution was developed in Step 4. Future analyses can replace these fragility curves with physics-based curves derived from numerical or physical models.

Step 6: Building Classification. In this step, each building is classified into an existing building typology and matched to the corresponding fragility curve.

Step 7: Probabilistic Damage Analysis and Sensitivity Test. The probabilities of building damage are estimated for each building and then aggregated at different spatial resolutions. In this final step, the sensitivity tests to quantify the aleatory and epistemic uncertainties involved in this framework are also estimated. 


\subsection{Community Study Site: Seaside, Oregon}

The US Pacific Northwest is threatened by the Cascadia Subduction Zone (CSZ) hazard (Fig. 2). The CSZ is located at the converging area between Juan de Fuca Plate and North American Plate, extending from Vancouver Island (Canada) to northern California. The City of Seaside, Oregon, USA, is located at approximately the geographic center of the CSZ and used as the study site for this work. Seaside has been described as one of the most vulnerable cities to a CSZ event (Wood, 2007). The low lying city has $87 \%$ of its land within the tsunami inundation zone, and $89 \%$ of the employees work within the inundation zone (Wood, 2007). Seaside has approximately 5,700 buildings based on 2012 tax lot data, and building types range from single family homes to large condominiums and waterfront hotels. The commercial buildings have a range of construction types, number of stories, and dates of construction. The latter is particularly important because changes to the building codes for seismic design impacted the construction and thus the ability of a building to resist lateral loads. With this range of building types and exposure to a CSZ event, Seaside can be considered as a reasonable test bed for the tsunami damage assessment.

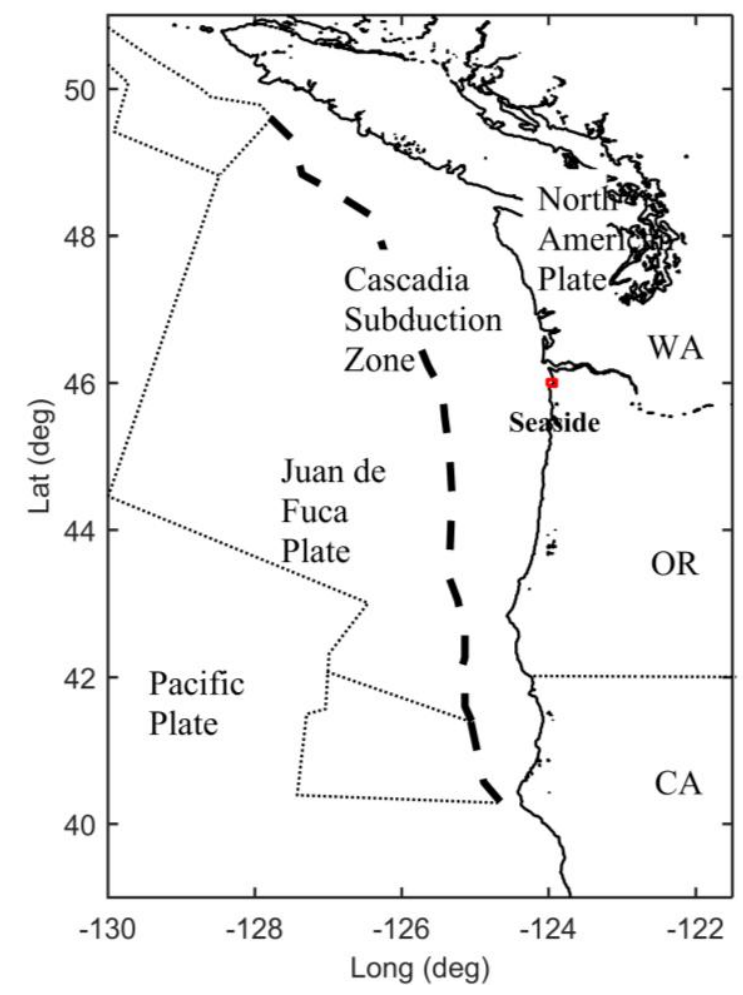

Fig. 2. Regional map of Cascadia Subduction Zone and study area (Seaside, Oregon) 
Fig. 3a shows an aerial view of Seaside, while Fig. 3b shows a detailed view of the inset central area. Point 1 indicates a representative observation location at the shoreline. The Necanicum River and Neawanna Creek separate the city from south to north and flow out to the ocean at the northern edge of city. The extent of the tsunami inundation for most full-rupture CSZ scenarios covers approximately $90 \%$ of the city, and the possible earliest arrival time of the initial tsunami wave at Point 1 shown in Fig. 3a is only 20-40 minutes (PC16).
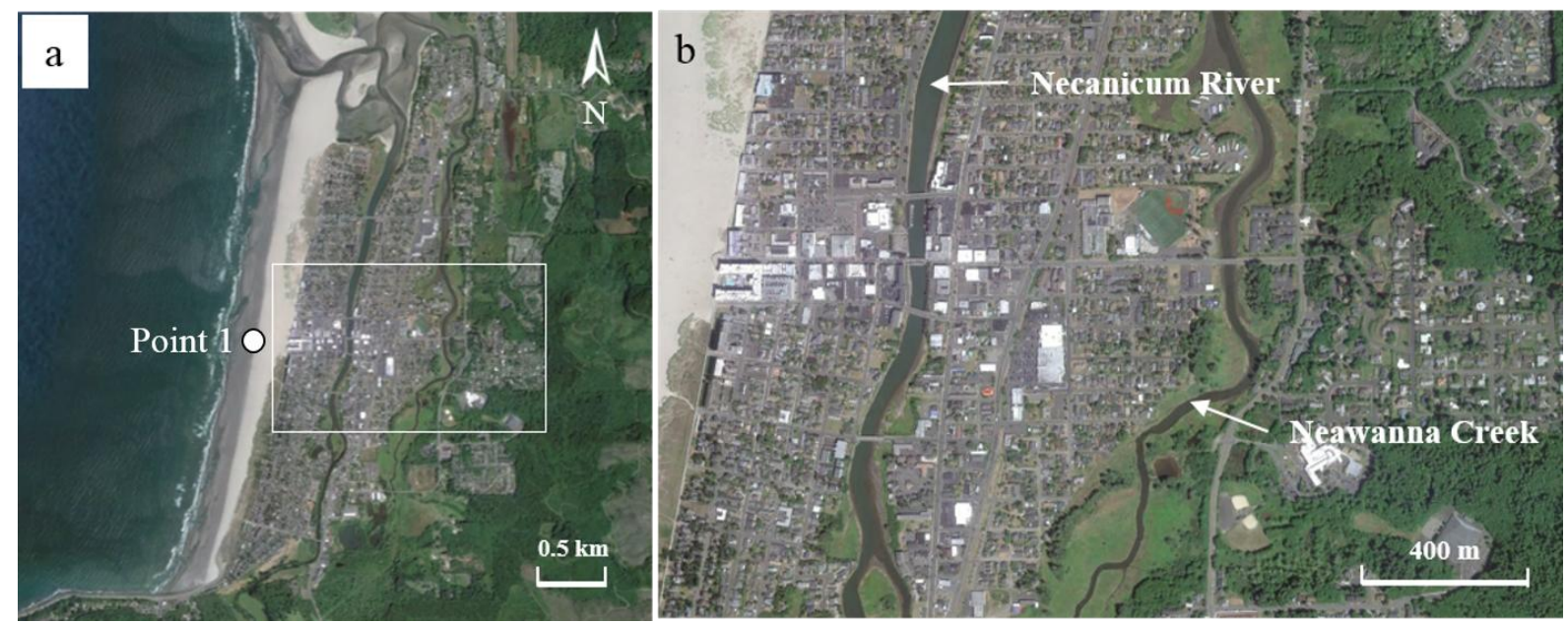

Fig. 3. (a) An aerial photograph of Seaside, Oregon (images modified from Google Earth). (b) Detailed area of Seaside (inner box region at Fig. 3a).

A probabilistic tsunami hazard assessment (PTHA) for Seaside has been performed by González et al. (2009). They suggested the integration of numerical tsunami inundation modeling with the methodology used for probabilistic seismic hazard assessment (PSHA). González et al. (2009) developed a maximum tsunami wave amplitude map for a given annual probability of exceedance, such as a $P=0.01$ or $P=$ 0.002 (100- or 500-year event), using Seaside as an example case. However, they only examined 12 scenarios for the CSZ and provided the maximum inundation depth only. In addition, Priest et al. (2010) conducted a PTHA for Cannon Beach, Oregon with confidence levels for their tsunami inundation map as inferred from expert opinion of a 10,000-year record of turbidite events along the CSZ (Goldfinger et al., 2012). Similarly, Witter et al. (2013) developed inundation maps for Bandon, Oregon, classified into five sizes (S, M, L, XL, and XXL). Both studies utilized a 3-D dislocation model (Wang et al., 2003) of the CSZ for the initial tsunami slip condition and a numerical inundation model (Zhang and Baptista, 2008) to estimate probabilistic tsunami hazards. 


\section{Manuscript for submission COASTAL ENGINEERING}

Recently, PC16 performed probabilistic near-field tsunami hazard assessment at the CSZ for the city of Seaside utilizing similar probabilistic approaches. They implemented the new method to define a fault rupture of earthquake for tsunami generation modeling reflecting the uncertain nature of tsunami generation. They characterized the randomness of the fault slip distribution at the rupture area as a Gaussian distribution which assimilated to the existing inversion model results of the major tsunami events $(\mathrm{Mw}>\mathrm{8.7})$ at different subduction zones since 2004 India Ocean Tsunami. The Gaussian distribution was composed of three parameters: the moment magnitude of earthquake, the location of peak slip, and the shape of the fault slip along the strike direction. PC16 also utilized 72 scenarios as tsunami sources with different weighting factors assigned based on the occurrence rate of historic events at the CSZ and slip distributions. For tsunami generation and propagation, PC16 utilized the ComMIT/MOST model (Titov et al., 2011) which embedded the linear co-seismic dislocation model for slip from Okada, 1985 for the tsunami generation. For tsunami inundation, PC16 utilized COULWAVE (Lynett et al., 2002). Model domains consisted of three nested grids, named A, B, and C-Grid and the size and dimension of each grids were $1 \mathrm{~min}(400 \times 400)$, $3 \mathrm{sec}(800 \times 800)$ and $24 \mathrm{~m}(416 \times 390)$. The ComMIT/MOST model output from the C-Grid was not used and was replaced by the COULWAVE results. The numerical calculations were performed with a bare-earth bathymetry condition for each model and used a default Manning number, $\mathrm{n}=0.03$ in the friction term for both models. PC16 provided tsunami hazard metrics including annual exceedance probabilities of inundation depth, velocity, and momentum flux, which are used as the IMs for the tsunami fragility analysis in this work.

The vulnerability of this city to possible tsunami hazards, including estimates of damage (DomineyHowes et al., 2010; Wiebe and Cox, 2014) and life safety (Wang et al., 2015; Priest et al., 2016) have been widely studied by various research groups. Recent studies on life safety and tsunami evacuation at Seaside indicate the problems of existing evacuation routes and the necessity of evacuation shelters to minimize the casualties in the city (Wang et al., 2015). High floor level buildings may serve as a potential haven for evacuees; thus the damage estimation of such buildings is a priority task.

\subsection{Probabilistic Tsunami Hazard Assessment (PTHA) Results at Seaside, Oregon}

The outputs from the work in PC16 (Steps 1 - 4) are used as inputs for the tsunami damage assessment process (Steps 5-7) and are shown here briefly. Fig. 4 shows an example for Step 3 obtained by the PTHA analysis of PC16 conditioned on a full rupture CSZ event. The figure shows the annual probability of exceedance of the maximum inundation depth (Fig. 4a) and annual probability of 
exceedance of the momentum flux (Fig. 4b) at Point 1. For example, Fig. 4a shows that there is 0.001 annual probability of exceeding a $9.2 \mathrm{~m}$ inundation depth and a 0.0001 annual probability of exceeding a $14 \mathrm{~m}$ inundation depth at Point 1 . These levels correspond to the "1,000-year" and "10,000-year" events. In the same manner, Fig. $4 \mathrm{~b}$ shows that there is 0.001 annual probability of exceeding $150 \mathrm{~m}^{3} / \mathrm{s}^{2}$ momentum flux and 0.0001 annual probability of exceeding $530 \mathrm{~m}^{3} / \mathrm{s}^{2}$ momentum flux at Point 1 . Although only Point 1 is shown, the work of PC16 estimated the exceedance probabilities throughout the Seaside study area.
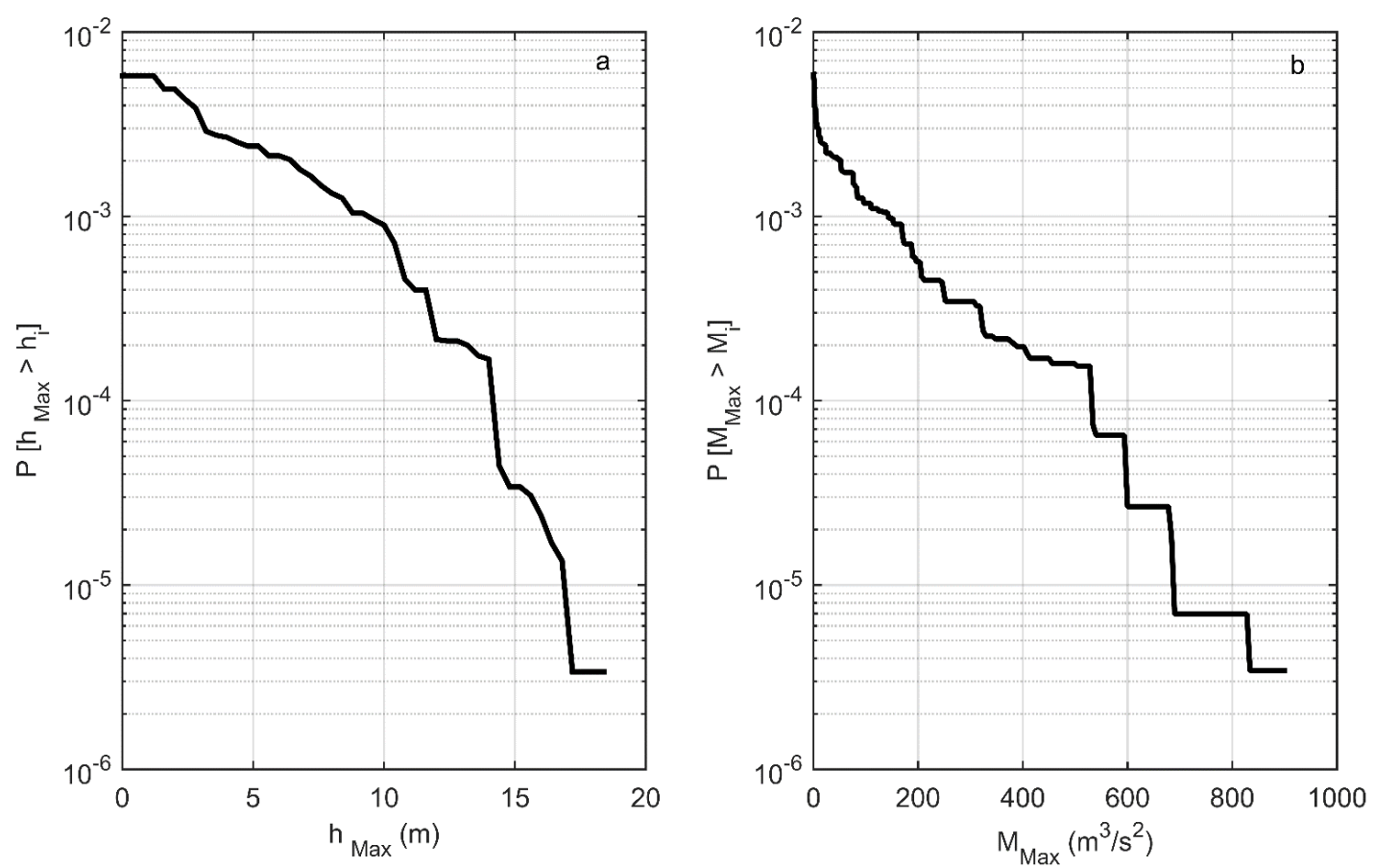

Fig. 4. Example of the annual exceedance probabilities of: (a) maximum inundation depth, and (b) momentum flux at Point 1 from PC 2016.

We have used 500, 1,000, 2,500-year return periods for our PTDA study. We have chosen the 500year event because the mean occurrence year of full-rupture earthquake event at the CSZ is 526 years, also it is the most probable scenario according to a study by the Oregon Department of Geology and Mineral Industries (DOGAMI). The 2,500-year is used because this is consistent with the 2,500 year return internal for structural design in ASCE (Chock, 2016). We also chose 1,000-year because it falls between 500 and 2,500 and to illustrate the trends in the probabilistic analysis. Fig. 5 shows the result of Step 4, which includes quantification of the spatial distribution of the IMs. Fig. 5a and c show the 1,000year full-rupture earthquake event over the tax lot parcel grid for the maximum inundation depth and the maximum momentum flux. For clarity in the descriptions of the results, we separate the detailed area 


\section{Manuscript for submission COASTAL ENGINEERING}

(Fig. 5b and d) into three regions: (1) Region A, extending from the shoreline to the Necanicum River (the first dotted line from left) where the most significant hazards and damages are predicted, (2) Region $B$, extending from the Necanicum River to the Neawanna Creek (the second dotted line from left), and (3) Region C, extending from the Neawanna Creek to the inland inundation limit of the worst scenario, about $2 \mathrm{~km}$ east of the shoreline. It can be seen in Fig. 5 that the spatial distributions of the intensity of $h_{\operatorname{Max}}$ and $M_{M a x}$ for the 1,000-year event at CSZ generally decrease from the shoreline to inland (from Region A to C). The range of the maximum inundation depth and momentum flux in is $4.0<h_{M a x}<10.0 \mathrm{~m}$ and $20.0<$ $M_{M a x}<150.0 \mathrm{~m}^{3} / \mathrm{s}^{2}$ in Region A, $1.0<h_{\operatorname{Max}}<5.0 \mathrm{~m}$ and $0.0<M_{\operatorname{Max}}<10.0 \mathrm{~m}^{3} / \mathrm{s}^{2}$ in Region B, and $0.0<$ $h_{M a x}<1.0 \mathrm{~m}$ and $0.0<M_{M a x}<5.0 \mathrm{~m}^{3} / \mathrm{s}^{2}$ in Region C. There are two distinct differences between the spatial distributions of $h_{M a x}$ and $M_{M a x}$. First, a relatively higher $h_{M a x}$ is found near the Necanicum River (6 to $7 \mathrm{~m}$ ) and also the Neawanna Creek $\left(3\right.$ to $5 \mathrm{~m}$ ), while there is no amplification of $M_{M a x}$ at the same regions. The increase of $h_{\operatorname{Max}}$ at the river and creek is caused from the confluence of two inundation flows: the shore-normal flow as the tsunami inundates the region from the coast and a secondary flow up the river and creek. A similar phenomenon had been observed during 2011 Tohoku tsunami in Japan (Mimura et al., 2011; Suppasri et al., 2012). Second, the intensity of $M_{\operatorname{Max}}$ decreases significantly across Region A, and shows spatially uniform and smaller intensities at Regions B and C. 

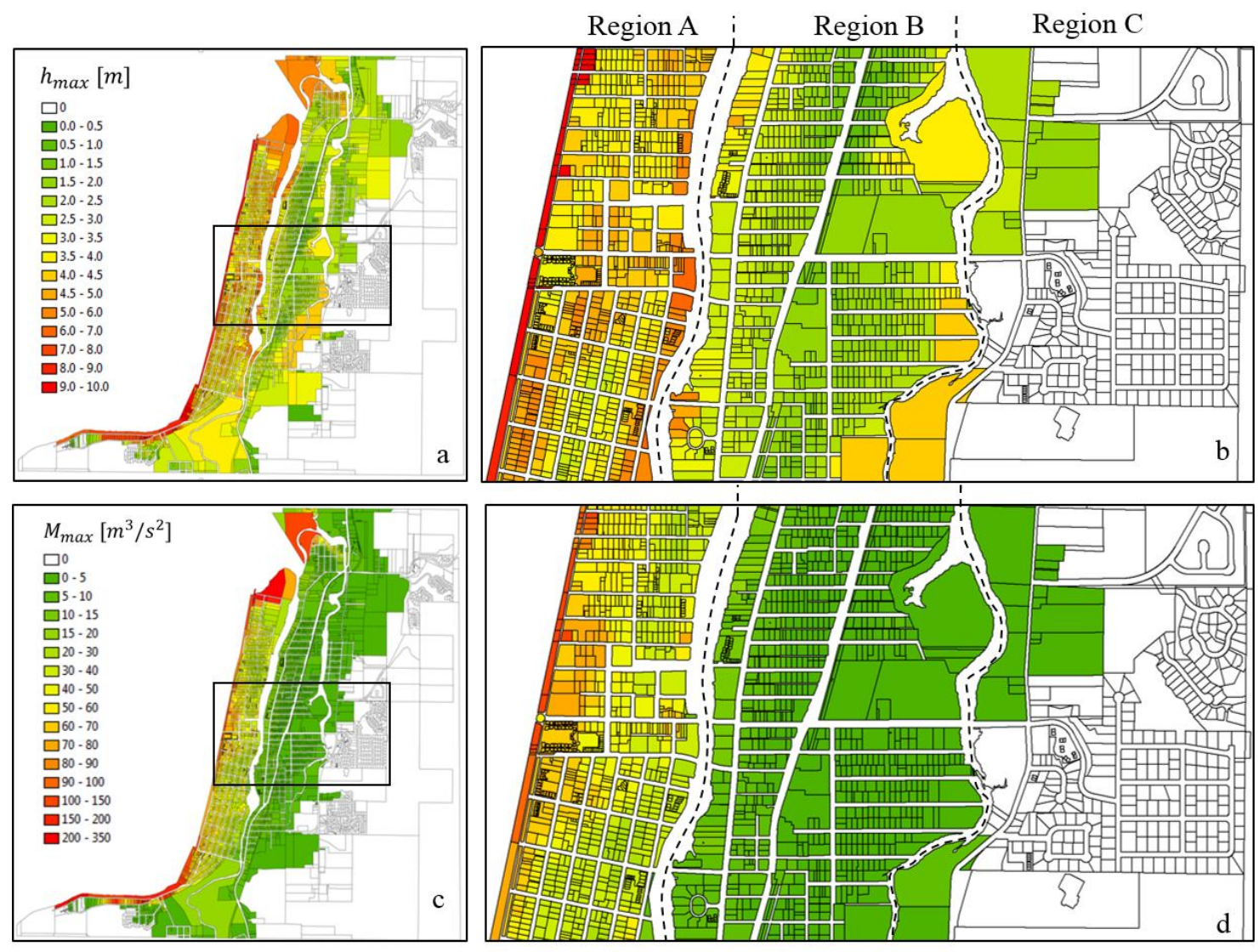

Fig. 5. Spatial distributions of $h_{\text {Max }}$ (top panels), and $M_{\text {Max }}$ (bottom panels) from 1,000-year event at CSZ over the tax lot shape file format at Seaside, OR.

\section{Fragility Assessment}

\subsection{Tsunami Fragility Curves}

A tsunami fragility curve provides a quantitative estimate of the probability of damage exceeding a given damage state on a building as a function of the tsunami intensity measure (IM) such as the maximum inundation depth, flow velocity, or momentum flux. Although fragility functions are widely used in other areas such as seismic (e.g., Whitman et al, 1997) and wind (e.g., Ellingwood et al., 2004), tsunami fragility functions were developed only recently after the 2004 Indian Ocean tsunami (Koshimura et al. 2009). The basic functional form of a tsunami fragility curve can be given by (e.g., Koshimura et al., 2009): 


$$
\begin{aligned}
& P(x)=\Phi[(x-\mu) / \sigma] \\
& P(x)=\Phi\left[\left(\ln (x)-\mu^{\prime}\right) / \sigma^{\prime}\right]
\end{aligned}
$$

where $P$ is the cumulative probability of damage, $\Phi$ is the standardized normal (lognormal) distribution function, $x$ is the intensity measure and $\mu$ and $\sigma\left(\mu^{\prime}\right.$ and $\left.\sigma^{\prime}\right)$ are the mean and standard deviation of $x(\ln$ $(x)$ ), determined by a linear regression analysis. The intensity measures considered in Koshimura et al. (2009) include the maximum inundation depth $\left(h_{M a x}\right)$, maximum flow velocity $\left(V_{M a x}\right)$, and maximum hydrodynamic force $\left(F_{M a x}\right)$. These were used to develop fragility curves from 2004 Indian Ocean tsunami based on the data collected in Banda Aceh, Indonesia. Koshimura et al. (2009) defined a framework in which they computed numerically the spatial distributions of maximum inundation depth and flow velocities at the sites and then matched the corresponding damage levels and building typologies using before and after satellite images. Using this framework, they developed fragility curves for wood and reinforced concrete buildings based on three IMs $\left(h_{\text {Max }}, V_{\text {Max }}\right.$, and $\left.F_{M a x}\right)$ through the regression analysis using a standardized normal (lognormal) function. A similar approach was adopted in different sites in Thailand based on surveyed damage levels and numerical model results by Suppasri et al. (2011). Similarly, other research groups used surveyed building damage and the observed inundation depth as the IM (Murao and Nakazato, 2010; Valencia et al., 2011; Reese et al., 2011) to develop fragility curves. After 2011 Tohoku tsunami, a total of 251,301 damaged buildings were surveyed in Japan by The Ministry of Land, Infrastructure, and Transportation (MLIT). A series of fragility curves were developed using the surveyed maximum inundation depth for six building construction materials, six damage states (e.g. minor, moderate, major, complete, collapse, and "washed-away"), and three classes for building floor levels (number of building stories), or ground surface topography conditions (Suppasri et al., 2013; Charvet et al., 2014; Suppasri et al., 2015). Recently, the Federal Emergency Management Agency (FEMA) suggested using momentum flux-based fragility curves for tsunamis in their unpublished Tsunami Methodology Technical Manual (FEMA, 2013). Fragility curves from FEMA (2013) assume that the lateral force capacity plays a significant role in determining the damage condition during the tsunami inundation, and utilizes the maximum momentum flux $\left(M_{\operatorname{Max}}\right)$ as an IM.

Following the work of Leelawat et al. (2014) and Suppasri et al. (2015), Table 1 summarizes the fragility curves developed since the 2004 Indian Ocean tsunami. It presents the source locations of each of the fragility function sets, the size of the sample (number of buildings), the development methodology, and the intensity measure (IM) utilized in the fragility curve sets. Four main methods have been used to 


\section{Manuscript for submission COASTAL ENGINEERING}

develop tsunami fragility curves, such as a satellite image analysis, field surveys, numerical model results, and analytic or empirical theories (FEMA, 2013). In addition, more than two methods are utilized together as a hybrid method (Koshimura et al., 2009; Valencia et al., 2011; Suppasri et al., 2011; Gokon et al., 2014). These hybrid methods utilize either satellite images or field surveys to determine the damage state of building and numerical simulations to estimate other types of IMs such as the maximum velocity or hydrodynamic force. In comparing the fragility curves developed over the past 10 years, it is worth noting that significant variations can be found for fragility curves developed for similar building typologies and damage states. These variations can be partially explained from the limited sources for the development of fragility curves and local variations in different study sites such as unconsolidated methodologies to determine building typology and different damage states (Tarbotton et al., 2015).

Table 1. Summary of developed fragility curves since 2004 Indian Ocean tsunami (modified from Suppasri et al., 2015)

\begin{tabular}{|c|c|c|c|c|c|}
\hline Source & Country/Location & Sample & Method & $\mathrm{IM}$ & Reference \\
\hline \multirow{4}{*}{$\begin{array}{l}2004 \text { Indian } \\
\text { Ocean }\end{array}$} & $\begin{array}{l}\text { Indonesia/ } \\
\text { Banda Aceh }\end{array}$ & 48,910 & SI, NS & $\begin{array}{l}h_{\operatorname{Max}}, V_{\operatorname{Max}} \\
F_{\text {Max }}\end{array}$ & Koshimura et al. (2009) \\
\hline & $\begin{array}{l}\text { Indonesia/ } \\
\text { Banda Aceh }\end{array}$ & 2,576 & SI, FS & $h_{\operatorname{Max}}$ & Valencia et al. (2011) \\
\hline & $\begin{array}{l}\text { Thailand/ } \\
\text { Phang Nga, } \\
\text { Phuket }\end{array}$ & 4,596 & $\mathrm{FS}, \mathrm{NS}$ & $\begin{array}{l}h_{\operatorname{Max}}, V_{\operatorname{Max}} \\
F_{\operatorname{Max}}\end{array}$ & Suppasri et al. (2011) \\
\hline & $\begin{array}{l}\text { Sri Lanka/SW } \\
\text { coast }\end{array}$ & 1,535 & FS & $h_{\operatorname{Max}}$ & $\begin{array}{l}\text { Murao \& Nakazato } \\
\text { (2010) }\end{array}$ \\
\hline $\begin{array}{l}2009 \text { American } \\
\text { Samoa }\end{array}$ & $\begin{array}{l}\text { American Samoa/ } \\
4 \text { Sites }\end{array}$ & 6,239 & SI, NS & $\begin{array}{l}h_{\operatorname{Max}}, V_{\operatorname{Max}} \\
F_{\operatorname{Max}}\end{array}$ & Gokon et al. (2014) \\
\hline 2010 Chile & Chile/Dichato & 915 & SI, FS & $h_{\operatorname{Max}}$ & Mas et al. (2012) \\
\hline \multirow{3}{*}{2011 Tohoku } & $\begin{array}{l}\text { Japan/ } \\
\text { Miyagi Prefecture }\end{array}$ & 157,640 & SI, FS & $h_{\operatorname{Max}}$ & $\begin{array}{l}\text { Koshimura \& Gokon } \\
\text { (2014) }\end{array}$ \\
\hline & Japan/East coast & 251,301 & FS & $h_{\operatorname{Max}}$ & Suppasri et al. (2013) \\
\hline & Japan/Ishinomaki & 63,605 & FS & $h_{\operatorname{Max}}$ & Suppasri et al. (2015) \\
\hline Hazus-EQ & United States & - & $\mathrm{AE}$ & $M_{M a x}$ & FEMA (2013) \\
\hline
\end{tabular}

Method: SI (Satellite images) NS (Numerical simulation), FS (Field survey), AE (Analytic or empirical theories) IM: $h_{\operatorname{Max}}$ (Maximum inundation depth), $V_{\operatorname{Max}}$ (Maximum velocity), $F_{M a x}$ (Maximum hydrodynamic force) and $M_{\operatorname{Max}}$ (Maximum momentum flux) 


\subsection{Maximum Inundation Depth Based Tsunami Fragility Curves}

The maximum inundation depth is widely used as an IM to develop tsunami fragility curves because it is measurable during a post-tsunami survey from indicators such as water marks and debris. Measurements of the flow velocity are extremely rare (Fritz et al., 2012). Moreover, the inundation depth can be predicted numerically with less variation compared to flow velocity (e.g., Park et al., 2013). Thus, most recent fragility curves use the maximum inundation depth as the basic IM. However, it is well known that the maximum inundation depth does not represent well the complex hydrodynamics and water-structure interactions during tsunami inundation (Valencia et al., 2011; Mas et al., 2012; Koshimura and Gokon, 2012; Suppasri et al., 2013; Charvet et al., 2014). For example, Suppasri et al. (2015) provide comparisons of two different sites from the 2011 Tohoku tsunami subjected to substantially different flow velocity fields. The authors highlight the necessity of an additional tsunami parameter such as the maximum velocity, momentum flux, hydrodynamic force, or debris concentration to better estimate damage.

\subsection{Maximum Momentum Flux Based Tsunami Fragility Curves}

The momentum flux can be used to represent the hydrodynamic forces (lateral force) or debris damming force on structures (Yeh, 2007; Koshimura et al., 2009; Yeh et al., 2014). As mentioned earlier, FEMA (2013) introduced new sets of tsunami fragility curves for building damage, which comprises of 36 building types (materials, types and floor level), three damage states, and seven seismic building code design level. The new damage fragility curves use the maximum momentum flux $\left(M_{M a x}\right)$ to represent the lateral force induced from the inundation flow, which then induces building damage. The lateral hydrodynamic tsunami flow force $\left(F_{T S}\right)$ on an idealized building is given by:

$$
F_{T S}=K_{d}\left(0.5 \rho_{s} C_{d} B\left(M^{\prime}\right)\right)
$$

where $K_{d}$ is a coefficient related to the shielding or debris impact that has a default value of $K_{d}=1.0, \rho_{\mathrm{s}}$ is the fluid density, $C_{d}$ is the drag coefficient that has a default value as $C_{d}=2.0$ in FEMA P-646 (2012) for a regular rectangular building shape, $B$ is building width normal to flow direction, and $M^{\prime}$ is median maximum momentum flux. $B$ is a representative width for each of the 36 building types, and $M^{\prime}$ characterizes the lateral tsunami force on the buildings accounting for hydrodynamic and debris damming forces. The damage fragility curve is given by: 


$$
P\left(M_{M a x}\right)=\Phi\left[\left(\ln \left(M_{M a x}\right)-\ln \left(M^{\prime}\right)\right) / \beta_{M}\right]
$$

where $M_{M a x}$ is the given input maximum momentum flux from tsunami analysis modeling at a specific building, $M^{\prime}$ is the median value of the maximum momentum flux associated with building typology and damage state, which is determined under the assumption that the estimated tsunami lateral force from Eq. 3 is equal to the lateral capacity force of each building estimated from the Earthquake Model Technical Manual (FEMA, 2011). $\beta_{M}$ is the logarithmic standard deviation describing the total uncertainty of the damage associated with debris $\left(K_{d}\right)$, building dimensions $(B)$, and the estimated earthquake lateral force.

\subsection{Building Tsunami Fragility Curves}

This subsection provides details of the two existing fragility curve types developed based on $h_{\text {Max }}$ from Suppasri et al. (2013; "S2013 model" hereafter) and $M_{\text {Max }}$, from FEMA (2013; "FEMA model" hereafter) and compares the probability of exceeding a given damage state. In addition to difference in the IMs, the S2013 and FEMA models used different methods to classify building typologies (i.e. building materials, frame types, and number of floors) and the building damage states (DS) (i.e. minor or major damage). The S2013 model followed the building typology and damage state formats of Ministry of Land, Infrastructure and Transport (MLIT) of Japan. The FEMA model, on the other hand, followed the format of a previously developed multi-hazard model for estimating damage by flood, earthquake, and hurricane hazards referred to as the "HAZUS-MH" model (e.g., FEMA, 2002; FEMA, 2011). The differences between the two models are summarized in Table 2. For building typology, the S2013 model provides six classes of building material: wood (W), masonry (Ma), steel (S), reinforced concrete (RC), Brick (B), and a mixed material condition (Mix). The FEMA model provides seven classes: wood (W), steel (S), concrete (C), precast concrete (PC), reinforced masonry (RM), unreinforced masonry (UM), and mobile homes $(\mathrm{MH})$. Each type of building material can be further categorized into subtypes in the FEMA model. For example, a wood building can be classified as W1 or W2 building, depending on its size, i.e. smaller or greater than approximately $500 \mathrm{~m}^{2}\left(5,000 \mathrm{ft}^{2}\right)$, respectively. The steel and concrete building types are subdivided into five and three subtypes, respectively. Both steel and RC buildings can be further subdivided into three classes based on the number of stories. The S2013 model, however, classifies the buildings into three types based on number of stories as one, two, and more than three stories. On the other hand, the FEMA model classifies buildings as 'Low-Rise' ( $1-3$ stories), 'Mid-Rise' (4 - 7 stories), and 'High-Rise' ( $\geq 8$ stories). For Damage States, the S2013 model provides for six levels: minor, moderate, major, complete, collapse, and washed away. The FEMA model uses three 
damage states: moderate, extensive, and complete. Table 3 lists these damage state classifications and descriptions for the two models.

One of the significant differences between the S2013 and FEMA models is that the FEMA model provides a classification based on the year of construction while the S2013 does not. This date classification originates from the different seismic design codes enforced in the US throughout history which would affect the ability of the building to resist lateral loads from earthquakes, but not necessarily from tsunami loads. The FEMA model classifies the building design level into seven seismic design categories (SDCs) depending on the usage and age of the building. Of these, four categories are for 'common' buildings, and three categories are for 'special' buildings such as hospitals and emergency centers. These building parameters are utilized to determine $M^{\prime}$ in Eq. 3 and 4 , and show significant deviation depending on the SDCs. Generally, higher SDCs are buildings designed to withstand larger lateral forces and that have improved detailing requirements. Thus, it is possible that these structures would also have improved capacity to withstand the tsunami induced lateral forces. It is noted that the FEMA model does not consider the ability of a structure to reduce the horizontal loads with elevated foundations or large openings (FEMA P-646, 2012). In Suppasri et al. (2015), the authors did not find any correlation between year of construction and intensity of building damage based on their study of 526 residential wooden houses surveyed in Japan after the 2011 Tohoku tsunami. This may be due to the overall inability for wooden houses to resist tsunami forces either from buoyancy loads, lateral loads, or a combination of the two.

Table 2. Building typologies and damage classification for S2013 and FEMA fragility curves

\begin{tabular}{|c|c|c|c|c|c|c|}
\hline IM & Model/Sources & $\mathrm{DS}$ & Material & $\mathrm{N}_{\mathrm{SF}}{ }^{(1)}$ & Stories & Seismic code \\
\hline \multirow{6}{*}{$h_{\operatorname{Max}}$} & \multirow{6}{*}{$\begin{array}{l}\text { S2013 model } \\
\text { / } 2011 \text { Tohoku Tsunami }\end{array}$} & Minor & $\mathrm{W}$ & & \multirow{6}{*}{$\begin{array}{l}1^{(2)} \\
2 \\
\geq 3\end{array}$} & \multirow{6}{*}{ None } \\
\hline & & Moderate & $\mathrm{Ma}$ & & & \\
\hline & & Major & $\mathrm{RC}$ & & & \\
\hline & & Complete & S & 1 & & \\
\hline & & Collapse & B & & & \\
\hline & & Washed away & Mix & & & \\
\hline \multirow{7}{*}{$M_{M a x}$} & \multirow{7}{*}{$\begin{array}{l}\text { FEMA model } \\
\text { / Hazus-MH model }\end{array}$} & & $\mathrm{W}$ & 2 & \multirow{7}{*}{$\begin{array}{l}1-3 \text { (Low) }^{(3)} \\
4-7(\mathrm{Mid}) \\
\geq 8(\mathrm{High})\end{array}$} & Pre \\
\hline & & & S & 5 & & Low \\
\hline & & Moderate & $\mathrm{C}$ & 3 & & Moderate \\
\hline & & Extensive & $\mathrm{PC}$ & 2 & & High \\
\hline & & Complete & $\mathrm{RM}$ & 2 & & Special-High \\
\hline & & & UM & 1 & & Special-Moderate \\
\hline & & & MH & 1 & & Special-Low \\
\hline
\end{tabular}


${ }^{(1)}$ : Number of subtypes in each in building typology; ${ }^{(2)}$ : Story information is only applicable for wood and RC structures in S2013 model; ${ }^{(3)}$ : Number of stories for wood (W) and mobile homes (MH) in FEMA model are not provided

Table 3. Damage state (DS) comparisons

\begin{tabular}{|c|c|c|}
\hline Models & DS & Description \\
\hline \multirow[t]{6}{*}{$\begin{array}{l}\text { S2013 } \\
\text { model }\end{array}$} & Minor & $\begin{array}{l}\text { No significant structural or nonstructural damage, possibly only minor } \\
\text { flooding }\end{array}$ \\
\hline & Moderate & Slight damage to nonstructural components \\
\hline & Major & Heavy damage to some walls but no damage in columns \\
\hline & Complete & Heavy damage to several walls and some columns \\
\hline & Collapse & Destructive damage to walls and several columns \\
\hline & Washed away & Washed away, only foundation remained, totally overturned \\
\hline \multirow[t]{3}{*}{$\begin{array}{l}\text { FEMA } \\
\text { model }\end{array}$} & Moderate & $\begin{array}{l}\text { Less than } 25 \% \text { economic loss but no long-term building closure and collapse } \\
\text { probability }\end{array}$ \\
\hline & Extensive & $\begin{array}{l}25-100 \% \text { economic loss, } 50 \% \text { of long-term building closure, and local } \\
\text { collapse of building. }\end{array}$ \\
\hline & Complete & $\begin{array}{l}100 \% \text { economic loss, long-term building closure or more than partial or full } \\
\text { collapse, including washed away. }\end{array}$ \\
\hline
\end{tabular}

Fig. 6 shows an example of the fragility curves discussed previously, with detailed information of each fragility curve summarized in Table $4 \mathrm{a}$ and b. Fig. 6a from the S2013 model shows four fragility curves (different building materials) for a single damage state (collapse). The thin solid and dashed lines show fragility curves for a one story wood structure (W1) and a two-story wood structure (W2), respectively. Thick solid and dashed lines show the fragility curves for two-story RC structures and three (3) or more story RC structures, respectively. It can be seen in Fig. 6a that there is little difference in the fragility curves for varied number of stories of wood structures, while the fragility curves for RC buildings are more sensitive to the number of stories. Fig. $6 \mathrm{~b}$ shows the fragility curves for wood structures based on the hydrodynamic forces developed by Koshimura et al. (2009) and the FEMA model in terms of momentum flux. It can be seen that the FEMA model gives a much lower damage probability for a given value of the momentum flux compared to that of Koshimura et al. (2009).

Fig. 6c shows the fragility curves for three damage states of low-rise ( $1-3$ stories), low seismic design level, reinforced concrete (RC) moment frame buildings from the FEMA model. Since moderate and extensive fragility curves are same for the low-rise condition, there are only two curves in Fig. 6c: a thin solid line (moderate and extensive damage) and a thick solid line (complete damage). Fig. 6d shows the differences of four seismic design categories (SDCs), Pre, Low, Moderate, and High codes, for the 
mid-rise (4 - 7 stories) and a moment frame RC building for a complete damage state. The thin solid and dashed lines show the fragility curves for pre and low SDCs, and the thick solid and dashed lines show the fragility curves for moderate and high SDCs. Pre and low SDC curves are similar, but the moderate and high SDC curves show increasingly higher fragility curves. In other words, the improved seismic design standards would also enable the building to withstand greater tsunami forces. Whether or not that is indeed the case of open to future research.
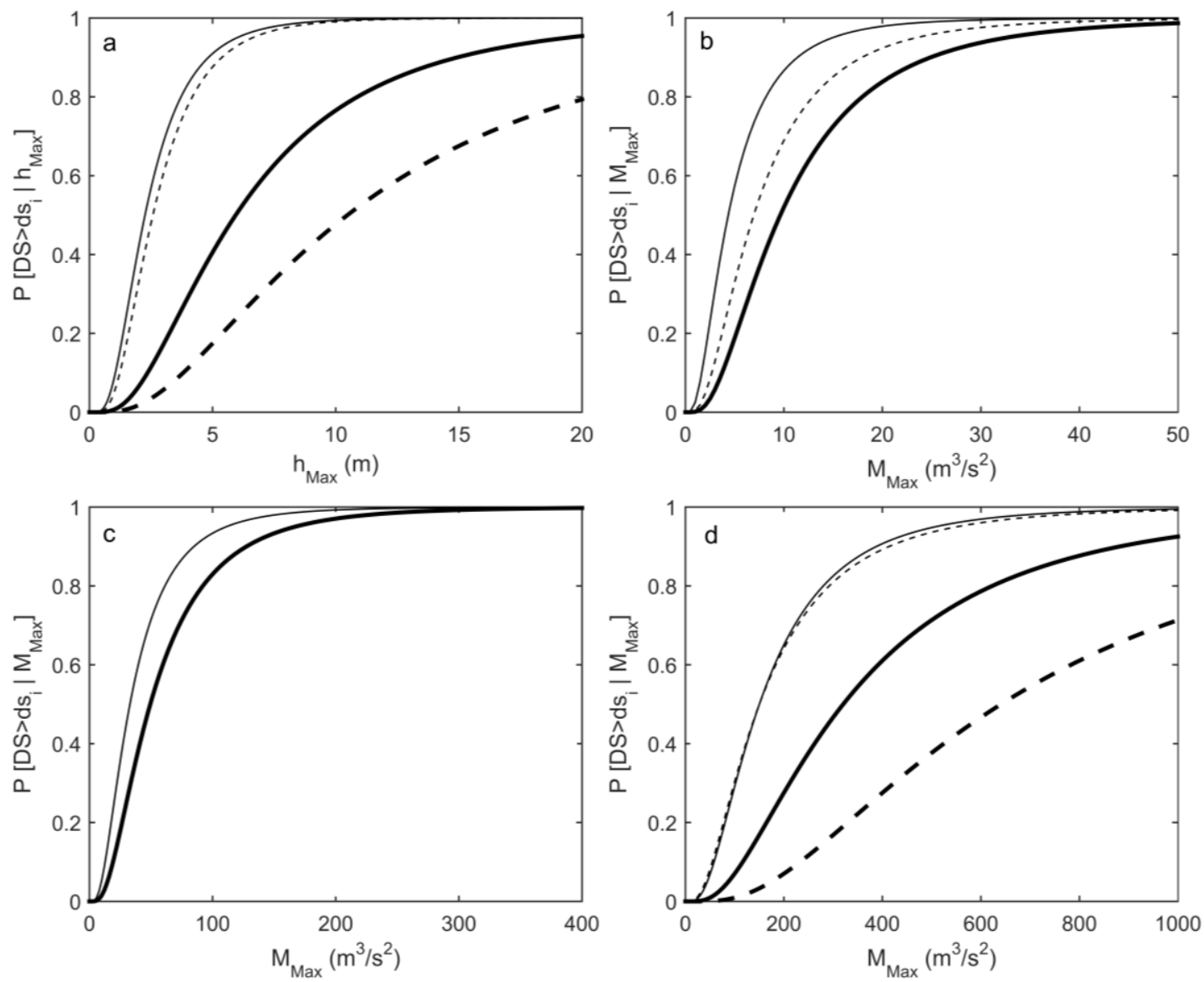

Fig. 6 Examples of tsunami fragility curves based on two IMs, $h_{\text {Max }}$ or $M_{\text {Max }}$ : (a) S2013 model 'Collapse' damage fragility curves based on $h_{M a x}$ for one-story wood (thin solid), two-story wood (thin dash line), two-story RC (thick solid), and three or more story RC structures (thick dash); (b) Wood structure fragility curves based on $M_{\text {Max }}$. The thin solid line presents the wood structure fragility curve from Koshimura et al. (2009), and the thin dashed and thick solid lines represent W1 and W2 from the FEMA model; (c) FEMA model fragility curves for RC moment frame buildings with $1-3$ stories. The thin solid line represents both 'Moderate' and 'Extensive' damage state fragility curves, and the thick solid line represents 'Complete' damage state fragility curves; (d) FEMA model 'Complete' damage state fragility 
curves for RC moment frame 4 - 6 story buildings for four different Seismic Design Categories, Pre (solid thin), Low (dashed thin), Moderate (solid thick), and High (dashed thick).

Table 4a. Detailed information of fragility curves I

\begin{tabular}{lllllllll}
\hline Fig. 5 & Eq. & $I M$ & $\begin{array}{l}\mu^{\prime} \\
{[\mathrm{m}]}\end{array}$ & $\begin{array}{l}\sigma^{\prime} \\
{[\mathrm{m}]}\end{array}$ & $D S$ & SDCs & Descriptions & Ref \\
\hline (a) & 2 & $h_{\operatorname{Max}}$ & 0.81 & 0.59 & Collapse & None & Wood, one-story & $(1)$ \\
& 2 & $h_{\operatorname{Max}}$ & 0.95 & 0.57 & Collapse & None & Wood, two-story & $(1)$ \\
& 2 & $h_{\operatorname{Max}}$ & 1.78 & 0.72 & Collapse & None & RC, two-story & $(1)$ \\
& 2 & $h_{\operatorname{Max}}$ & 2.35 & 0.79 & Collapse & None & RC, $>3$ stories & $(1)$ \\
\hline
\end{tabular}

IM: Intensity Measure; DS: Damage State; SDCs: Seismic Design Categories. ${ }^{(1)}$ Suppasri et al. (2013);

Table 4b. Detailed information of fragility curves II

\begin{tabular}{|c|c|c|c|c|c|c|c|c|c|c|}
\hline $\begin{array}{l}\text { Fig. } \\
5\end{array}$ & Eq. & $I M$ & $\begin{array}{l}\mu \\
{\left[\mathrm{m}^{3} / \mathrm{s}^{2}\right]}\end{array}$ & $\begin{array}{l}\sigma \\
{\left[\mathrm{m}^{3} / \mathrm{s}^{2}\right]}\end{array}$ & $\begin{array}{l}M^{\prime} \\
{\left[\mathrm{f}^{3} / \mathrm{s}^{2}\right]}\end{array}$ & $\begin{array}{l}\beta_{M} \\
{\left[\mathrm{f}^{3} / \mathrm{s}^{2}\right]}\end{array}$ & $D S$ & $S D C s$ & Descriptions & Ref \\
\hline \multirow[t]{3}{*}{ (b) } & 1 & $\mathrm{M}_{\operatorname{Max}}$ & 1.47 & 0.75 & & & Collapse $^{(4)}$ & None & Wood & (2) \\
\hline & 4 & $\mathbf{M}_{\operatorname{Max}}$ & & & 247 & 0.74 & Complete & None & Wood, $<5,000 \mathrm{ft}^{2}$ & (3) \\
\hline & 4 & $\mathbf{M}_{\operatorname{Max}}$ & & & 343 & 0.73 & Complete & None & Wood, $\geq 5,000 \mathrm{ft}^{2}$ & (3) \\
\hline \multirow[t]{3}{*}{ (c) } & 4 & $\mathbf{M}_{\operatorname{Max}}$ & & & 1,170 & 0.74 & Moderate & Low & $\begin{array}{l}\text { RC, } 1-3 \text { stories, } \\
\text { Moment Frame }\end{array}$ & (3) \\
\hline & 4 & $\mathbf{M}_{\operatorname{Max}}$ & & & 1,170 & 0.74 & Extensive & Low & $\begin{array}{l}\text { RC, } 1-3 \text { stories, } \\
\text { Moment Frame }\end{array}$ & (3) \\
\hline & 4 & $\mathbf{M}_{\operatorname{Max}}$ & & & 1,758 & 0.74 & Complete & Low & $\begin{array}{l}\text { RC, } 1-3 \text { stories, } \\
\text { Moment Frame }\end{array}$ & (3) \\
\hline \multirow[t]{4}{*}{ (d) } & 4 & $\mathbf{M}_{\operatorname{Max}}$ & & & 5,347 & 0.74 & Complete & Pre & $\begin{array}{l}\text { RC, } 4-7 \text { stories, } \\
\text { Moment Frame }\end{array}$ & (3) \\
\hline & 4 & $\mathbf{M}_{\operatorname{Max}}$ & & & 5,347 & 0.79 & Complete & Low & $\begin{array}{l}\text { RC, } 4-7 \text { stories, } \\
\text { Moment Frame }\end{array}$ & (3) \\
\hline & 4 & $\mathbf{M}_{\operatorname{Max}}$ & & & 11,407 & 0.79 & Complete & Mod. & $\begin{array}{l}\text { RC, } 4-7 \text { stories, } \\
\text { Moment Frame }\end{array}$ & (3) \\
\hline & 4 & $\mathbf{M}_{\operatorname{Max}}$ & & & 22,813 & 0.79 & Complete & High & $\begin{array}{l}\text { RC, } 4-7 \text { stories, } \\
\text { Moment Frame }\end{array}$ & (3) \\
\hline
\end{tabular}

${ }^{(2)}$ Koshimura et al. (2009); ${ }^{(3)}$ FEMA (2013); ${ }^{(4)}$ Koshimura et al. (2009) bisected the damage state of buildings as destroyed or survived, which may correspond to 'Collapse' damage condition in Table 3.

\section{Building Classification (Typology)}

Classification of buildings into different typologies is an essential component of a fragility assessment. The most credible method to obtain accurate building information is based on a combination of field surveys and data collected from engineering drawings for particular buildings. However, field surveys are labor intensive and require a large commitment of time and resources; therefore, such surveys are practical for only a small number of buildings, and it is difficult to classify the building stock of a 19 


\section{Manuscript for submission COASTAL ENGINEERING}

large community. Moreover, engineering drawings may not be readily available, particularly for older buildings that were designed before the advent of computer aided drawing (CAD) or electronic means of archival. Further, building owners may be unwilling or unable to provide such information.

In this study, in consideration of issues listed in the previous paragraph, three data sources methods are used to develop the database of building information needed for the fragility assessment: (1) Tax lot data (TLD), (2) images from Google Street View (GSV), and (3) a field survey based on an adapted version of the FEMA-154 Rapid Visual Screening (RVS). In the United States, tax lot data are typically available in the public domain and updated on an annual basis. For this study, the 2012 tax lot data were obtained for Clatsop County, Oregon (Wiebe and Cox, 2014). The tax lot database was accessible and managed using geographic information system (GIS) software. The database is composed of individual parcels for tax lots (shown in Fig. 5 and 7). TLD provides general features of each parcel such as the centroid coordinates, size $\left(\mathrm{m}^{2}\right.$ or $\left.\mathrm{ft}^{2}\right)$, address, date of construction, owner, real market value, and land value. The database also contains its own classification rule which is called a 'stat class'. The stat class composes of three-digit numbers and each number represents building information. The first digit identifies whether the land use is zoned as a residential, commercial, or industrial parcel. The second digit provides information regarding the building occupancy and use. The third digit provides additional information such as the number of floors (Dominey-Howes et al. 2010; Wiebe and Cox 2014). The methodology to use the 'stat class' is briefly summarized in Table 5. It can be seen that the tax lot information can be used to provide the construction material, floor levels, building typology, size of the parcels, and year of construction. Thus, TLD method allows us to classify the building inventory quickly over a large region. However, the TLD does not have the exact details information of the building materials, floor levels (only some floor levels for some building types are provided), and the building resistance system. Moreover, the TLD may be outdated due to remodeling, renovation, or changes in building use.

To complement the TLD and to account for some its inherent limitations, Google Street View (GSV) method was used to fill in missing data and to validate the data. For example, with an image of a building façade, GSV allows for a quick evaluation of building features such as number of floors, construction type, and general age based on architectural details. It is possible that GSV can also be used to obtain more detailed building information such as the elevation of the first floor and the number of windows and other openings that can affect the tsunami hydrodynamic forces. GSV can also be combined with satellite imagery to estimate a building width, shape, proximity to other buildings, and susceptibility to debris 
hazards. In addition to GSV, a field survey was performed by the authors using an adapted version of FEMA P-154 (2015) Rapid Visual Screening (RVS) method for 12 buildings (major hotels at ocean front and public facilities) to verify the tax lot data for a small subset of buildings.

Overall, results from the GSV and RVS methods show good agreement with the tax lot data (TLD) method. We examined more than 20 ocean front residential building and 20 commercial buildings at the center of Seaside with GSV. We found that all residential building materials and floors levels matched with the TLD method. Approximately 15 to $20 \%$ of the older commercial buildings were made of brick or wood instead of RC. In addition, 9 of the 12 buildings surveyed by the RVS method agreed with the TLD method with regard to floor level and building material.

Table 5. Applied building classification standard using the 'stat class' in tax lot data of Seaside, OR.

\begin{tabular}{|c|c|c|c|c|c|}
\hline Class & & Description & Material & Floors & Classification \\
\hline$<400$ & $<200$ & 1 stories & Wood & 1 & W1 \\
\hline \multirow{5}{*}{$\begin{array}{l}\text { Residential } \\
\text { Buildings }\end{array}$} & (a) 'c' & $\geq 2$ stories & & 2 & W2 \\
\hline & $\geq 6$ & & & & \\
\hline & $\geq 200$ & Multiple family, $\geq 2$ stories & & 2 & W2 \\
\hline & $410-414$ & Motel \& Hotel & $\mathrm{RC}$ & 4 & $\mathrm{C} 1$ \\
\hline & 420,421 & Apartment (Low) & Wood & 2 & W2 \\
\hline$\geq 400$ & 422,423 & Apartment (Mid, High) & & 4 & \\
\hline Commercial & 446,447 & Large market, Merchandising store & Wood & 2 & W2 \\
\hline \multirow[t]{5}{*}{ Buildings } & 485 & Parking structure, Garage & $\mathrm{RC}$ & 4 & $\mathrm{C} 1$ \\
\hline & 498,511 & Parking lots & None & - & None \\
\hline & 563 & Church & Wood & 2 & W2 \\
\hline & 900 & Condominium & $\mathrm{RC}$ & 7 & $\mathrm{C} 1$ \\
\hline & Others & Other commercials & $\mathrm{RC}$ & 1 & $\mathrm{C} 1$ \\
\hline
\end{tabular}

Fig. 7 shows the spatial distribution of the buildings in the City of Seaside. Fig. 7a, b, and c show the building classification map for building types (W1, W2, C1, C2, and S1), building stories (1 to $\geq 6$ ), and building SDCs for Oregon based on the date of construction as listed in Table 6. Only a few non-wood buildings are classified as $\mathrm{C} 2$ or S1 according to RVS, thus non-wood buildings are treated as $\mathrm{C} 1$ buildings for simplicity in Fig. 7a. Table 7 summarizes some of the building information, also shown in Fig 7a. It can be seen that 1,098 tax lot parcels are found at Region A, and among them, 36\% of parcels are wood structures and 54\% are RC or other structures, all of which will be designated as RC structures henceforth since these are the majority. The remaining proportion (10\%) indicate empty parcels. Regions B and C consist of 855 and 403 parcels, respectively, with a majority of wood structures in both regions 
(62\% and 68\%, respectively). The downtown area of Seaside (Region A) has a larger percentage of commercial than residential buildings.

Table 6. Seismic Design Codes applied for the buildings in Oregon.

\begin{tabular}{lll}
\hline Seismic Design Level & Year Adopted & Year Applied \\
\hline Pre-Code & Before 1974 & Before 1979 \\
Low-Code & $1974-1990$ & $1979-1995$ \\
Moderate-Code & $1990-1998$ & $1995-2003$ \\
High-Code & After 1998 & After 2003 \\
\hline
\end{tabular}
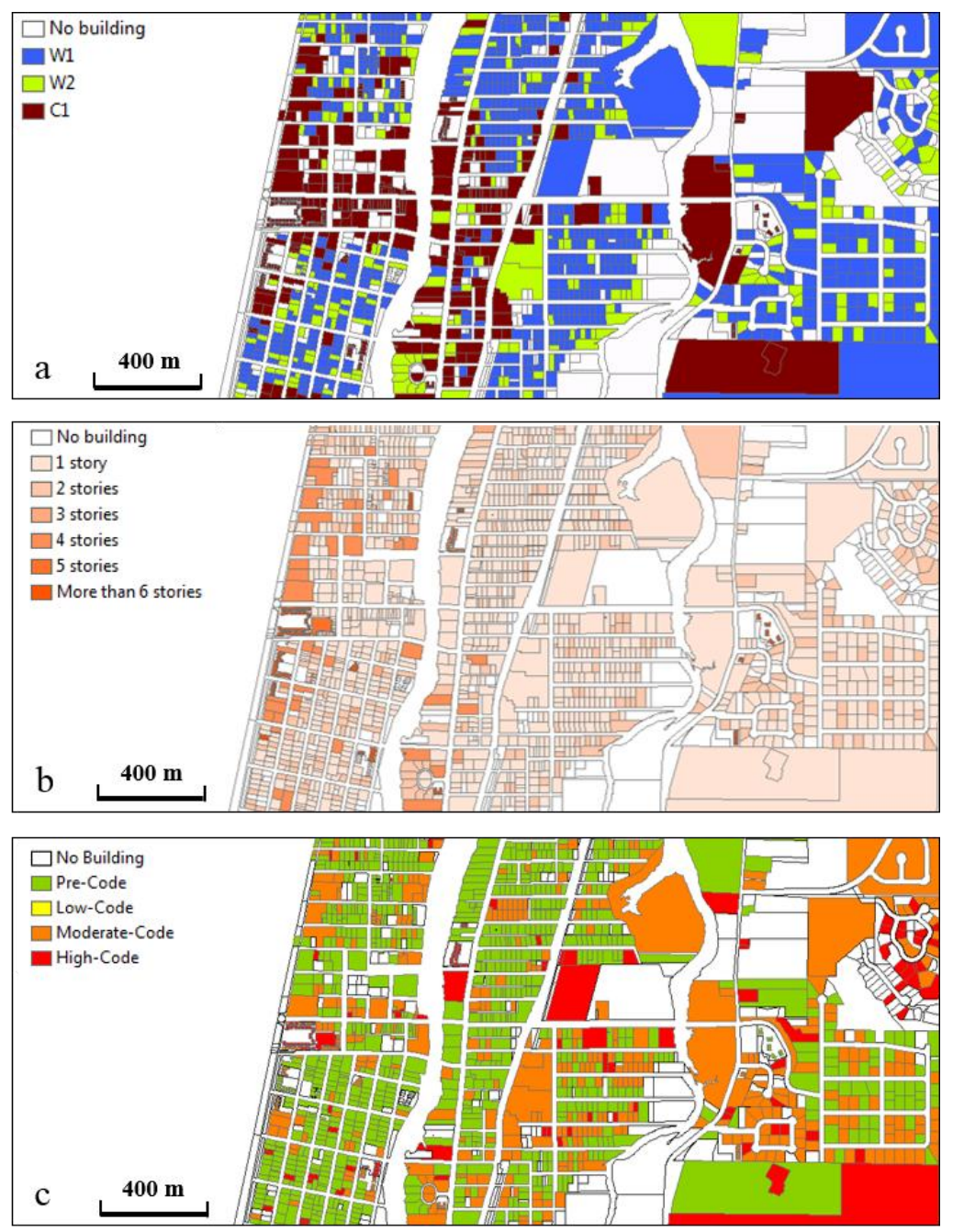

Fig. 7. Building classification map for (a) building type, (b) number of stories, and (c) building Seismic Design Code for the central area of the City of Seaside. 
Table 7. Number of buildings by type and region for the central area of the City of Seaside.

\begin{tabular}{llll}
\hline Region & $\mathrm{N}_{\text {Wood }}(\%)$ & $\mathrm{N}_{\mathrm{RC}}(\%)$ & $\mathrm{N}_{\text {Total }}$ \\
\hline $\mathrm{A}$ & $394(35.9)$ & $592(53.9)$ & 1098 \\
$\mathrm{~B}$ & $530(62.0)$ & $193(22.6)$ & 855 \\
$\mathrm{C}$ & $274(68.0)$ & $41(10.2)$ & 403 \\
\hline
\end{tabular}

Region A: Shoreline to Necanicum River; Region B: Necanicum River to Neawanna Creek, Region C: Neawanna Creek to the inland inundation limit.

The detail information of floor levels and SDCs in Fig. 7b and c are summarized in Table 8. It is noted here that no differences are found between different SDCs for wood structures in the FEMA model and that the three special SDCs referred to in Table 2 are not included in this study. It is also worth noting that taller and newly built buildings are located in Region A, which has a higher tsunami intensity.

Table 8. Detailed number of buildings by type and region in detail area of Seaside (Fig. 7a).

\begin{tabular}{|c|c|c|c|c|c|c|c|c|c|}
\hline \multirow[t]{4}{*}{ Region } & \multicolumn{2}{|c|}{$\mathrm{N}_{\text {Wood }}(\%)$} & \multicolumn{6}{|c|}{$\mathrm{N}_{\mathrm{RC}}(\%)$} & \\
\hline & \multirow{3}{*}{ W1 } & \multirow{3}{*}{ W2 } & \multicolumn{3}{|c|}{ Stories } & \multicolumn{4}{|c|}{ Seismic Design Codes ${ }^{(a)}$} \\
\hline & & & $1-3$ & $4-7$ & $\geq 8$ & Pre & Low & Moderate & High \\
\hline & & & Low & Mid & High & $<1979$ & $\begin{array}{l}1979- \\
1995\end{array}$ & $\begin{array}{l}1995- \\
2003\end{array}$ & $\begin{array}{l}\geq \\
2003\end{array}$ \\
\hline $\mathrm{A}$ & 284 & 110 & 116 & 464 & 12 & 151 & 67 & 331 & 43 \\
\hline B & 426 & 104 & 101 & 92 & 0 & 65 & 35 & 10 & 83 \\
\hline $\mathrm{C}$ & 221 & 53 & 9 & 32 & 0 & 21 & 16 & 1 & 3 \\
\hline
\end{tabular}

${ }^{(a)}$ Seismic Design Codes classification adapted for the state of Oregon

\section{Probabilistic Damage Analysis}

The 1,000-year event of the maximum inundation depth and momentum flux (Fig. 5) at CSZ is used to demonstrate the PTDA methodology using the S2013 and FEMA fragility curves. For the quantitative comparison of damage states (DS) from two fragility curve models, we utilize similar DS conditions for each model based on Table 4: 'Collapse' for the S2013 model and 'Complete' damage for the FEMA model. We apply the detailed typology of buildings in Section 4 based on number of floors, seismic codes, materials, and building frames.

Fig. 8 shows the spatial distributions of building damage probability of Seaside due to the 1,000-year event originating from the CSZ. Fig. $8 \mathrm{a}$ and $\mathrm{c}$ show the probability of equaling or exceeding the collapse damage estimated using the S2013 model $\left(h_{\text {Max }}\right)$ and the probability of equaling or exceeding complete damage obtained using the FEMA model $\left(M_{M a x}\right)$. Fig. $8 \mathrm{~b}$ and $8 \mathrm{~d}$ show the central region of the city in detail. In general, the results obtained using both models show a similar distribution of probable damage. It can be seen that the probability of damage decreases from the shoreline moving inland, following the 
pattern of decreasing intensity of $h_{M a x}$ and $M_{\text {Max }}$ shown in Fig. 5. Relatively smaller damage probabilities are found at the center of downtown (middle of Region A) where the most commercial buildings are located. Most residential buildings (classified as wood buildings) to the north and south of the downtown area show more than $80 \%$ probability of collapse or complete damage at Region A in both models. However, there are some distinct differences between two models. The S2013 model yields the results that show relatively higher damages near the Necanicum River and Neawanna Creek, and also relatively higher damages on Region B, when compared to the results obtained using the FEMA model. This is related to the higher flood levels near the river and creek, and it is possible these would overestimate the damage in these regions. On the other hand, the FEMA model shows higher damage levels for several of the RC buildings in the center of downtown.

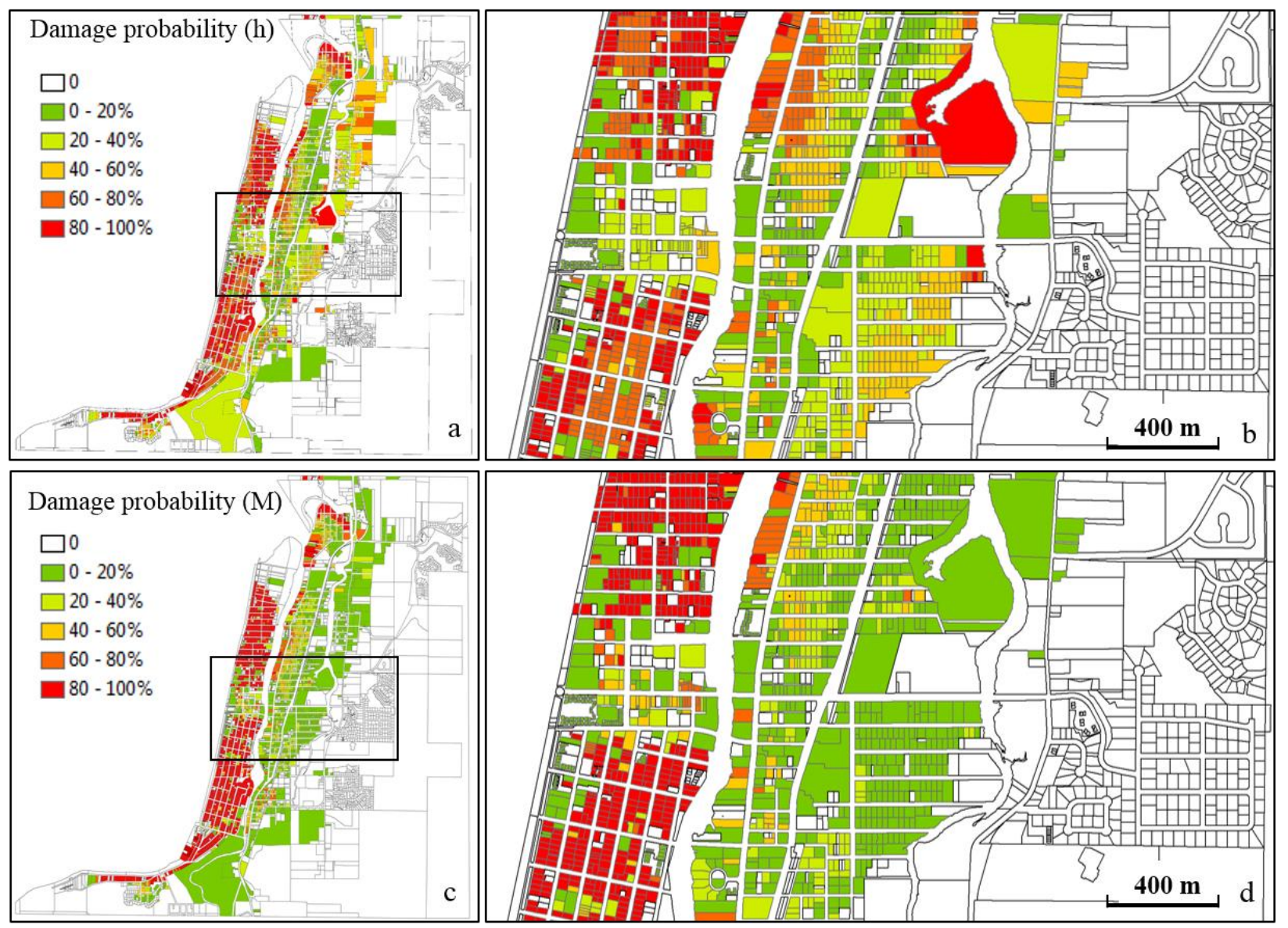

Fig. 8 Spatial distribution of probability of complete damage from 1,000-year event using two types of fragility curves: (a) S2013 model, (b) S2013 model central area of the City of Seaside, (c) FEMA model, and (d) FEMA model central area of the City of Seaside. 


\section{Manuscript for submission COASTAL ENGINEERING}

\section{Sensitivity Tests}

Each step of the probabilistic tsunami damage assessment (PTDA) described in section 2.1 contains the uncertainty due to the inputs or simplifying assumptions. Their quantitative impacts on the final damage probability could vary regionally, depending on the targeted tsunami events (e.g. 1000-year event) and building condition. For example, the uncertainties involved in tsunami generation models for 2,500-year event at Seaside would not be sensitive to the damage estimation of wood buildings near the coastline because those buildings are completely damaged or washed away. However, this is not necessarily true for RC buildings. In this section, a series of sensitivity tests are developed to quantify the significance of the possible uncertainty depending on building materials and location for the PTDA process. We investigate the impacts of aleatory uncertainty in the tsunami generation process and the epistemic uncertainty related to: (1) the hydrodynamic model (model friction), (2) the number of floor levels, (3) the design level (year of construction), and (4) the fragility curve models (different IMs). The sensitivity studies are performed on the central area of the City of Seaside shown in Fig 8b and d. Fig. 9 shows the centroid points of the tax lot parcels in this central area. We note that some buildings, such as the $\mathrm{u}$-shaped building near the $\mathrm{x}^{\prime}, \mathrm{y}^{\prime}$ origin, are composed of several tax lots. For this analysis, the coordinates of the building are rotated with respect the shore normal direction $\left(x^{\prime}\right)$, and the shore parallel direction $\left(y^{\prime}\right)$. The tsunami intensity is fairly uniform in the shore parallel direction and thus the study region is divided from the shoreline $\left(x^{\prime}=0 \mathrm{~m}\right)$ to the inland limit of $x^{\prime}=1,300 \mathrm{~m}$ into sub-units with an interval of $50 \mathrm{~m}$ (dashed lines). The damage probability in each sub-unit is estimated as the mean damage probability across all parcels per sub-unit width $(50 \mathrm{~m})$. The damage is separated into wood and other buildings since a significant difference is expected in the damage probability based on building materials as

shown

in

the

sections

above. 


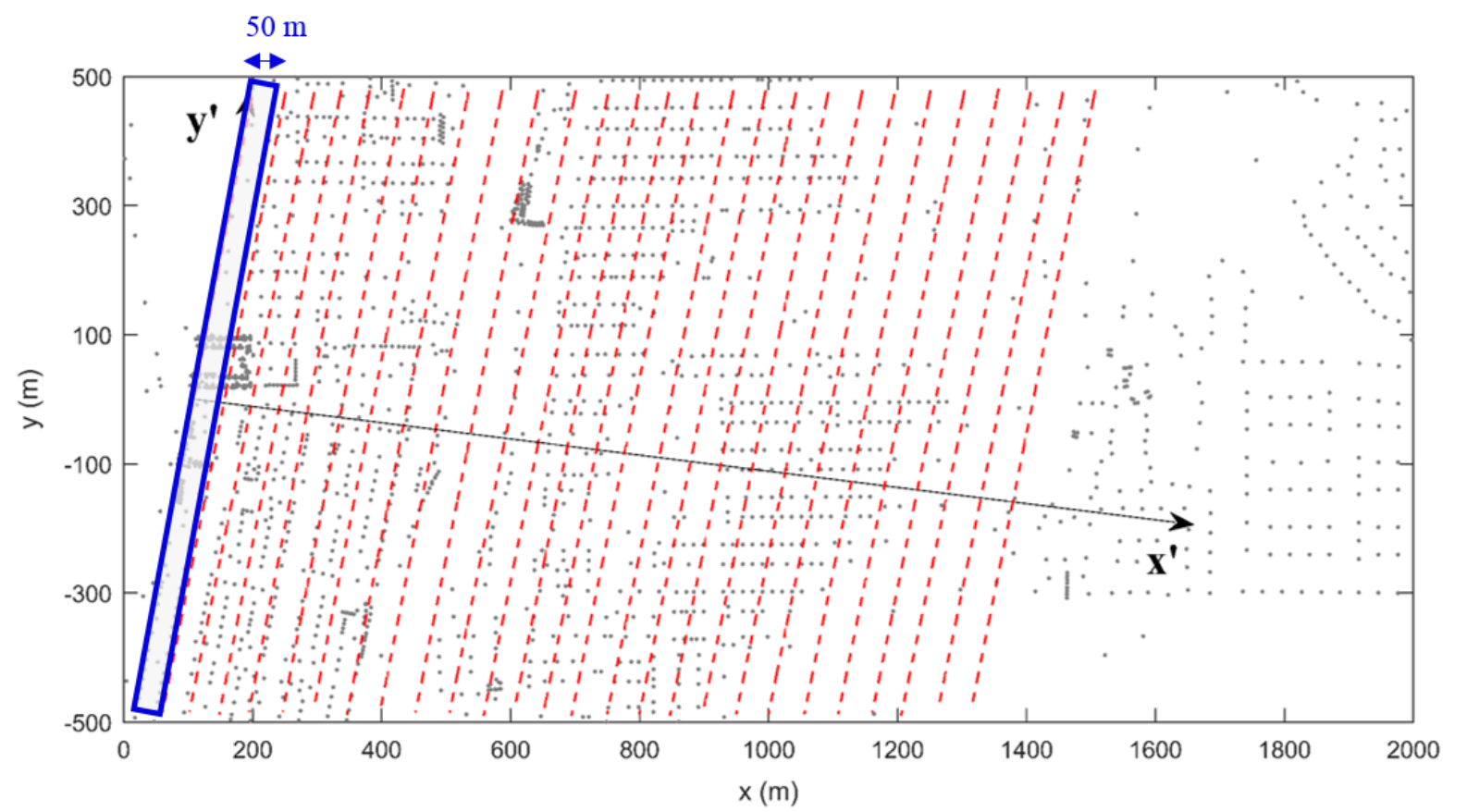

Fig. 9. The map of tax lot parcels applied in the sensitivity test. Each dot represents the centroid of tax lot. Box at the shoreline (blue) illustrates a sub-unit width $(50 \mathrm{~m})$. Dashed (red) lines illustrate other sub-units considered.

\subsection{Sensitivity to Tsunami Generation}

Fig. 10 shows the mean damage probabilities in each $50 \mathrm{~m}$ bin from the shoreline to the inland limits for the 500-, 1,000- and 2,500-year events at CSZ. The 1,000-year event is used as a reference value, and the 500-year and 2,500-year events are used to represent the possible aleatory uncertainty in the tsunami generation. Fig. 10a and 10b show the mean probability of the two groups of buildings, i.e. wood and other buildings, respectively, obtained using the FEMA model for complete damage. In these figures, the 500-year event is represented as a blue circle, the 1,000-year event as black triangles, and the 2,500-year event as red squares. Fig. 9c shows total number of wood (circles) and other (triangles) building parcels in each bin.

In general, a relatively large deviation of probabilities for complete damage is found between the 500year and 1,000-year events in Region A for both wood and RC structures. A relatively small deviation is found between the 1,000- and 2,500-year events for wood structures in Region A because most wood structures in Region A are essentially destroyed from the intensity of tsunamis exceeding the 1,000-year 
event. For the case of wood structures, Fig. 10a shows that both the 1,000-year and 2,500-year events result in high probabilities of complete damage (>95\%) in Region A $\left(x^{\prime} \leq 500 \mathrm{~m}\right)$, while the 500-year event generates moderately probabilities of complete damage ( $<60 \%)$. In Region B $\left(500<x^{\prime}<1,200 \mathrm{~m}\right)$, both the 1,000-year and 2,500-year events show a nearly linear decreases of the mean damage probabilities, while probabilities of complete damage are very low for the 500-year event. For RC structures, it can be seen from Fig. 10b that there are near zero probabilities of complete damage for these buildings for the 500-year event in all three regions. Both the 1,000- and 2,500-year events generate similar patterns of damage probability in Region A. It is worth noting that the peak of the mean damage probability for these events are not located at the shoreline, but at approximately $400 \mathrm{~m}$ from the shoreline just before reaching the Necanicum River. This observed damage pattern is due to the fact that Region A consists of a relatively large number of buildings with a large floor levels (hotels and condominiums), nearest to the shoreline, which are in general less susceptible to damage, while buildings further away from the shoreline are typically fewer stories and built using lower SDCs; thus these structures exhibit larger damage probabilities. Further inland from the Necanicum River $\left(x^{\prime}>500 \mathrm{~m}\right)$, the mean probability of complete damage decreases significantly and shows a near zero probability at Region B and beyond. 

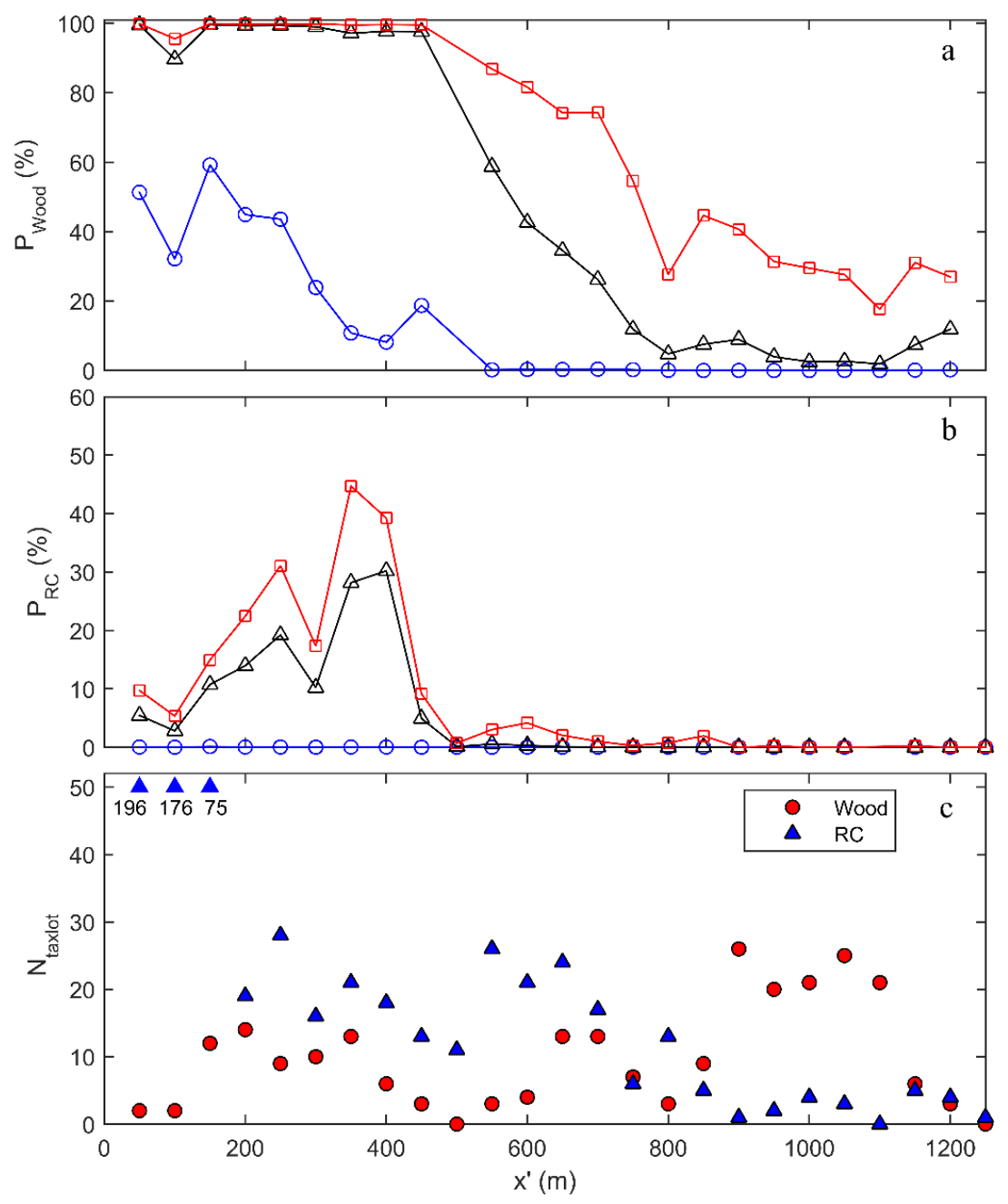

Fig. 10. Mean probability of complete damage for: (a) wood and (b) RC buildings with different tsunami events, 2,500-year (red square), 1,000-year (black triangle), and 500-year event (blue circle); (c) total number of wood (circle) and RC (triangle) buildings parcels in each bin.

\subsection{Sensitivity to Inundation Model Friction $(\mathrm{n}=\mathbf{0 . 0 2}, \mathbf{0 . 0 3}$, and 0.04$)$}

Friction terms are included in the inundation model to capture the dissipation effects from uneven bottom conditions during the propagation and inundation of a tsunami. It is well known that friction from large macro-roughness in the built and natural environment, such as building structures and vegetation, can significantly change the hydrodynamic fields (e.g. Koshimura et al. 2009; Bricker et al. 2015). It is important to define reasonable friction terms in order to obtain useful estimates of velocity and momentum flux since both of these flow parameters are significantly affected by the friction values used to model the inundation process (Park et al. 2013). In this study, a constant Manning number $(n=0.03)$ is 


\section{Manuscript for submission COASTAL ENGINEERING}

used as the central value for all scenarios. For the sensitivity test, a single scenario, chosen from the 72 scenarios presented in PC16 for the 1,000-year event, is used with two other Manning friction values: $n=$ 0.02 and $n=0.04$.

Fig. 11 shows the average probability of complete damage at each bin for the three different friction values. Fig. 11a and b show the mean probabilities of wood buildings and RC buildings, respectively, for the three Manning number conditions, $n=0.04$ (blue circle), $n=0.03$ (black triangle), and $n=0.02$ (red square) for complete damage states using the FEMA model. The same number of wood and RC parcels applied in this comparison as in Fig. 10c. For the case of wood structures (Fig. 11a) at Region A ( $x^{\prime} \leq 500$ m), all model results show an equally high probability of complete damage (approximately $100 \%$ ). For Region B $\left(500<x^{\prime}<1,200 \mathrm{~m}\right)$, the probability of complete damage decreases approximately linearly as $x^{\prime}$ increases moving shoreward. A smaller Manning number $(n=0.02)$ results in a higher probability of complete damage because, as expected, there is less energy dissipation of the flow. Therefore, larger peak velocities and momentum fluxes are observed, which in turn produce larger probabilities of damage. In the case of RC structures (Fig. 11b), all friction cases show a similar pattern of damage probabilities, with a somewhat larger variation for $300<x^{\prime}<400 \mathrm{~m}$ where the average probability is largest.

\subsection{Sensitivity to Floor Level (Low, Mid, and High-Rise)}

Fig. 12 shows the average probability of complete damage for structures with varying numbers of stories (Low-, Mid-, and High-Rise) using the FEMA model for the 1,000-year event. To evaluate the sensitivity of the probability of damage to the number of stories, four different conditions are assumed. First, the real distribution of floor building heights is obtained based on the building classification developed in Section 4. Second, three conditions were assumed for all RC buildings in the area, which are: (1) Low-Rise (1 - 3 floors), (2) Mid-Rise (4 - 7), and (3) High-Rise ( $\geq 8$ ). This sensitivity study was not extended to the wood buildings since the FEMA model does not include effects of floor levels for wood building typologies.

Fig. 12a shows the estimated average damage probabilities for RC buildings. The solid black line represents the estimated damage probability based on the building classification for number of stories described in Section 4. Three additional lines are shown for the fixed floor level assumptions such as Low-Rise (blue circle), Mid-Rise (red triangle), and High-Rise (green square) floor levels. Overall, higher damage probabilities are observed for structures with lower numbers of stories. In particular, Highand Mid-Rise floor conditions show similarly low (less than 5\%) damage probabilities at Region A, but 
the Low-Rise floor conditions shows significantly higher probabilities (up to 25\%) compared to other floor conditions at $x^{\prime}=400 \mathrm{~m}$. For reference, Fig. 12b shows the number of RC buildings classified into each of the floor level conditions based on the field observed data per 50-meter bin.
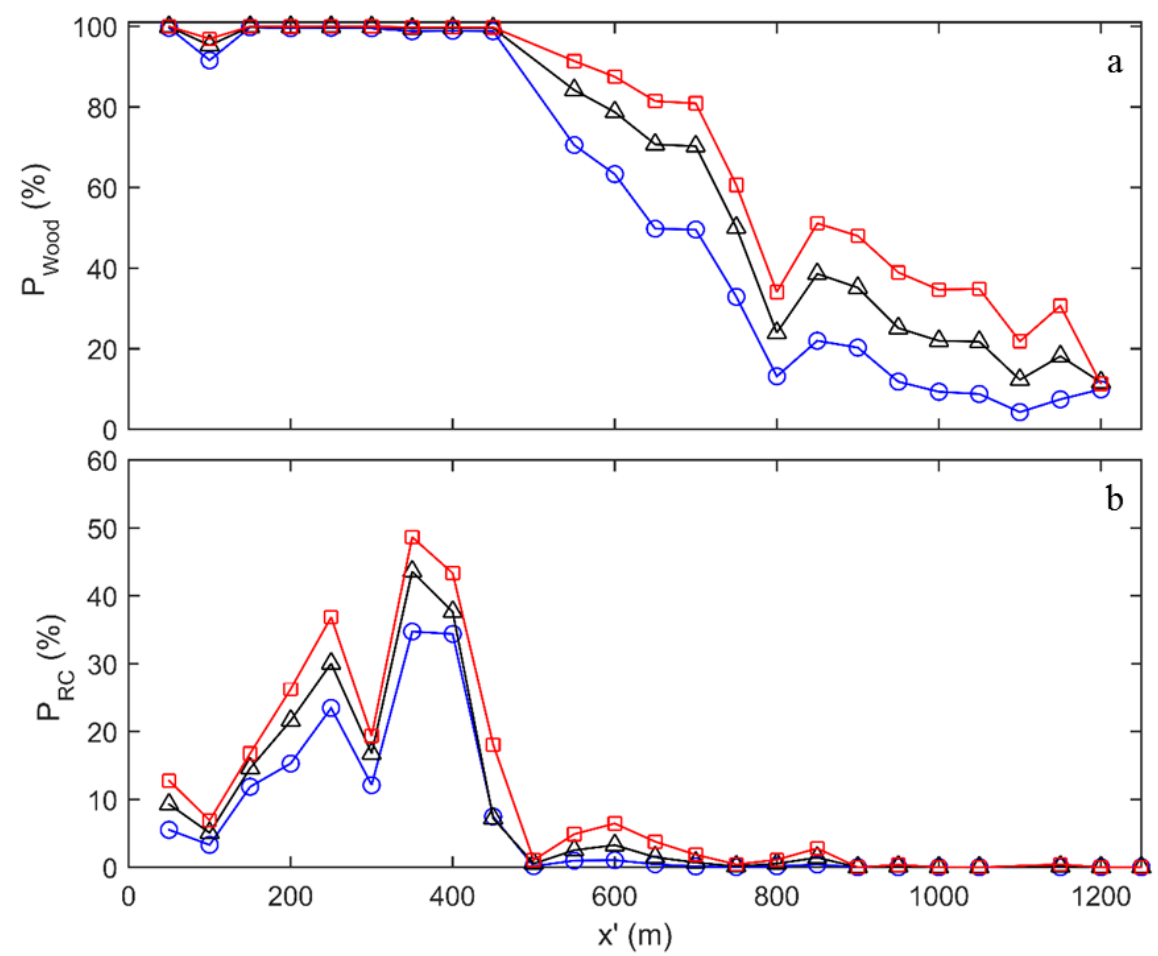

Fig. 11. Average probability of complete damage for (a) wood and (b) RC buildings with different friction terms, $n=0.02$ (red square), 0.03 (black triangle), and 0.04 (blue circle). 

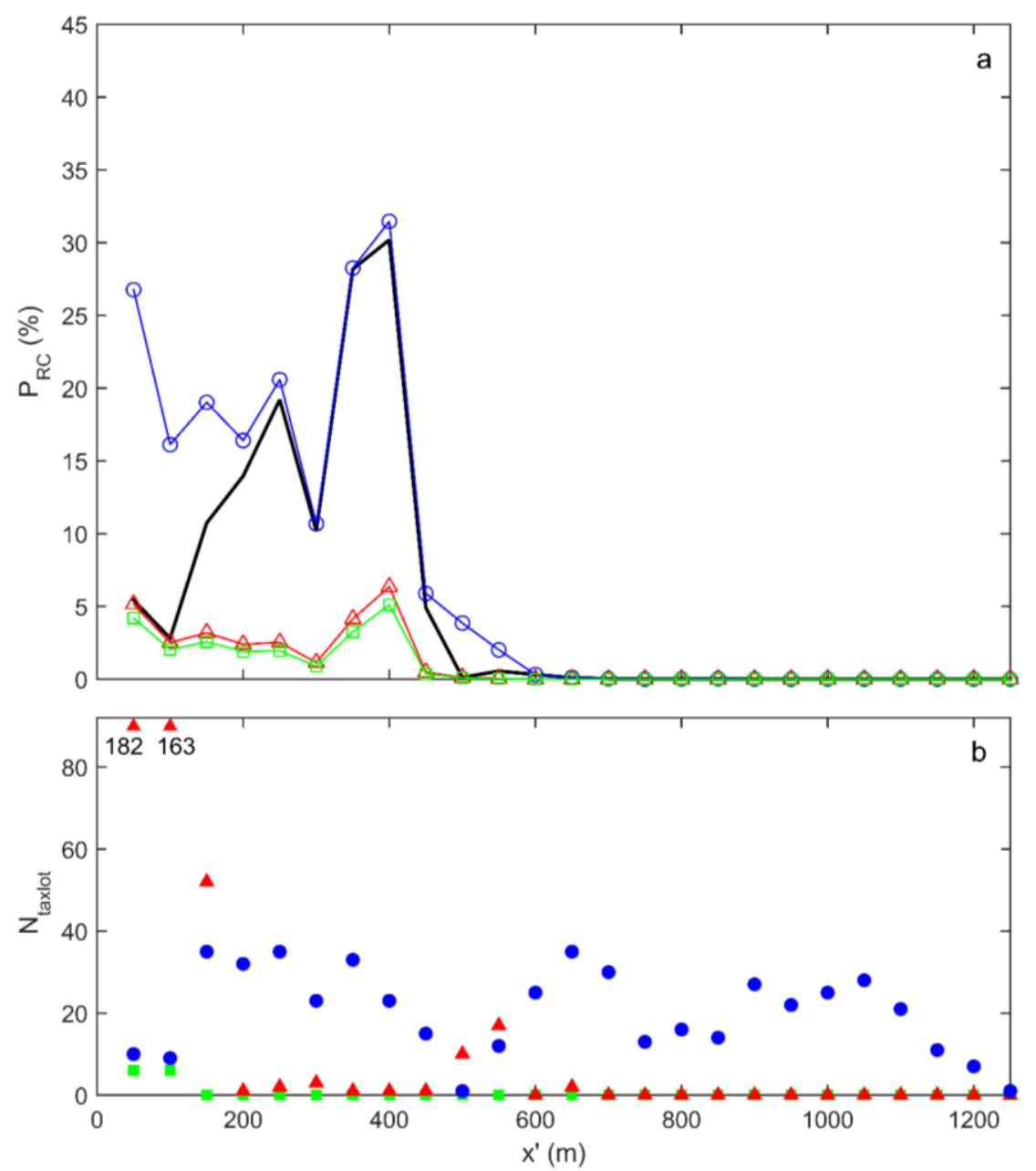

Fig. 12 Building damage sensitivity to building floor level information: (a) Solid line: results from observed floor level information; lines with markers: artificial uniform building distributions: Low-Rise (blue circles), Mid-Rise (red triangles), and High-Rise (green squares); (b) Distribution of floor level classification for observed building floor levels in each 50-meter bin.

\subsection{Sensitivity to Seismic Design Categories (Pre, Moderate, and High)}

Fig. 13 shows the average probability of complete damage with different Seismic Design Categories (SDCs) in the FEMA model (Pre-code, Low-code, Moderate-code, and High-code) for the 1,000-year event. Similar to the previous sensitivity test for the floor levels, we assume that all RC buildings in each scenario have a fixed SDC condition. Note that Low-code SDC and Pre-code SDC show minor differences in the FEMA model (e.g. Fig. 6d); these conditions were grouped for clarity. Focus is placed on RC buildings since there are no SDC provisions for wood structures in the FEMA model and thus wood buildings are also excluded for this sensitivity analysis. 
Fig. 13a shows the average probabilities for complete damage of RC buildings. The solid line represents the scenario using the field-determined SDCs for all RC buildings, based on year built. For each of the different SDC assumptions for RC buildings, results for three conditions are shown: (1) Precode (blue circles), (2) Moderate-code (red triangles), and (3) High-code (green squares). In general, higher probabilities of complete damage are observed when lower SDC conditions are assumed. The peak damage probability of the Pre-code SDCs (circles) is $42 \%$ at $x^{\prime}=200 \mathrm{~m}$. The solid line shows only a $13 \%$ probability of complete damage at the same location, indicating that the results would be sensitive to uncertainties in the SDCs considered. For reference, Fig. 13b shows the distribution of the number of RC buildings classified into the three SDC levels for the field data considered in each 50-meter bin.
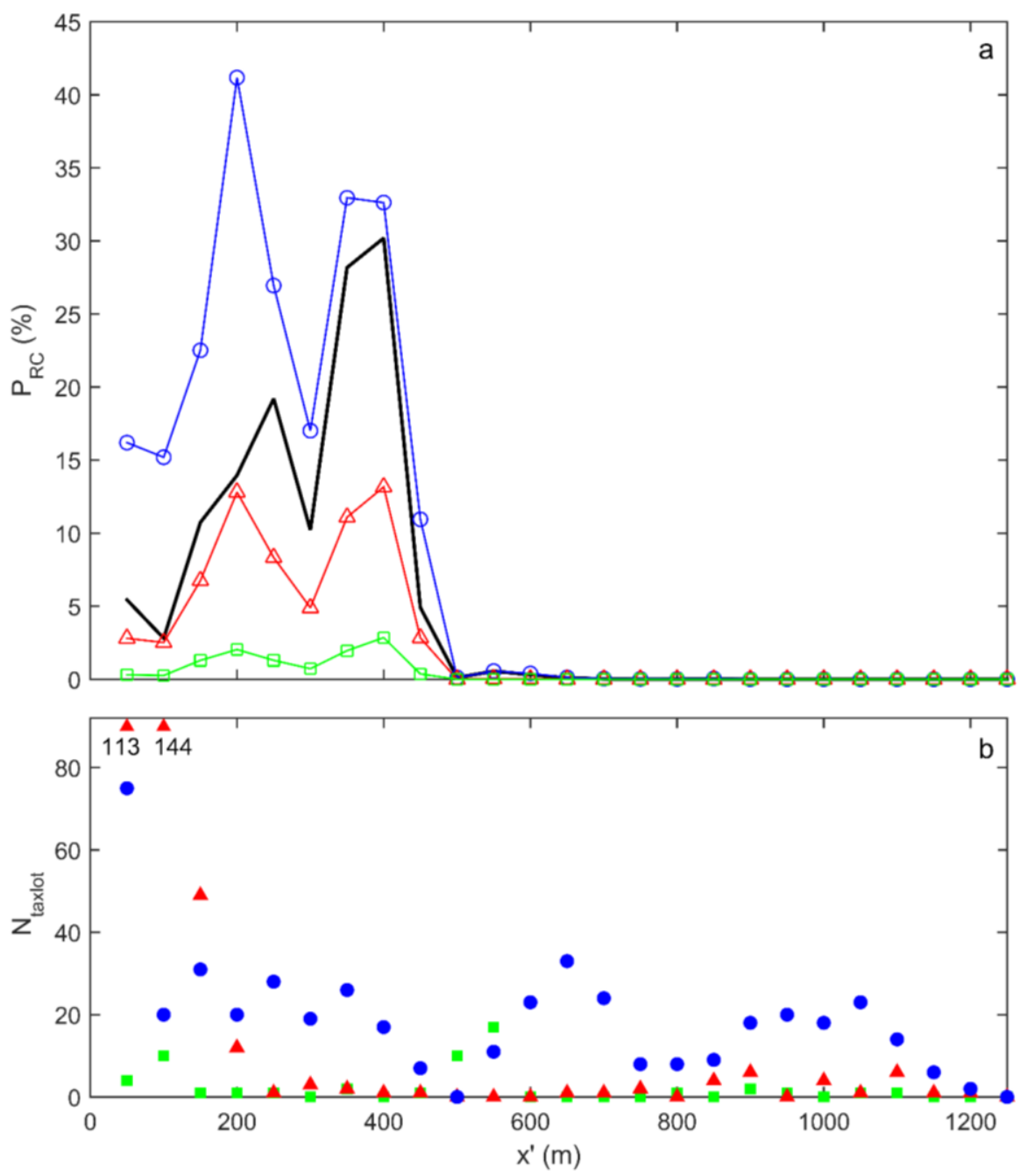

Fig. 13 (a) Building damage sensitivity to the building floor level information with different SDCs assumptions: Pre and Low-code (blue circles), Moderate code (red triangles), and High code (green 
squares). Solid line presents result from the correct SDC information. (b) Number of parcels used for bin averaging.

\subsection{Sensitivity to Fragility Curve Types $\left(h_{M a x}, M_{M a x}\right)$}

Fig. 14a and 14b show the average probability of complete damage for wood and RC buildings, respectively, for the 1,000-year (solid line) and 500-year (dashed line) events. Each damage estimation is performed based on either the S2013 model (black triangle \& inverse triangle) or the FEMA model (red circle and square). For reference, the number of wood and RC parcels considered in each 50-meter bin is shown Fig.10.

For the case of the wood structures (Fig. 14a), both the S2013 and FEMA model show large probabilities of complete damage in Region A for the 1,000-year event (solid lines), but they show a large deviation in damage probabilities in Region B $\left(500 \leq x^{\prime}<1200 \mathrm{~m}\right)$. The FEMA model predicts a linear decrease of damage probability as $x^{\prime}$ increases, while the S2013 model shows that the average damage probability decreases until $x^{\prime}=900 \mathrm{~m}$ and then increases as $x^{\prime}$ approaches the Neawanna creek $\left(x^{\prime} \sim 1,200\right.$ $\mathrm{m})$. These results are consistent with the high flood levels in the area and the fact that the S2013 model is a flow-depth based fragility model. For the 500-year event (dashed lines), the overall damage probabilities of both models are similar in Region A. However, the S2013 model shows an greater probability of complete damage by a factor of 3 at $x^{\prime}=450 \mathrm{~m}$, adjacent to the Necanicum River. In Region B, both models show distinct differences.

For the case of RC structures (Fig. 14b), the mean probability of complete damage from the 1,000-year event (solid lines) are less than $40 \%$ for both models in Region A. However, the location of the peak probability of damage using the FEMA model and S2013 model are observed at $x^{\prime}=400 \mathrm{~m}$ and $x^{\prime}=200 \mathrm{~m}$, respectively. For the 500-year event, the range of probability of complete damage for FEMA model is approximately 5 to $10 \%$ in Region A. On the other hand, the probability of complete damage is negligible (approximately zero) for the S2013 model. The differences in results here can be attributed in part to the fact that the two different fragility models (S2013 and FEMA) use different IMs (inundation depth or momentum flux, respectively). 


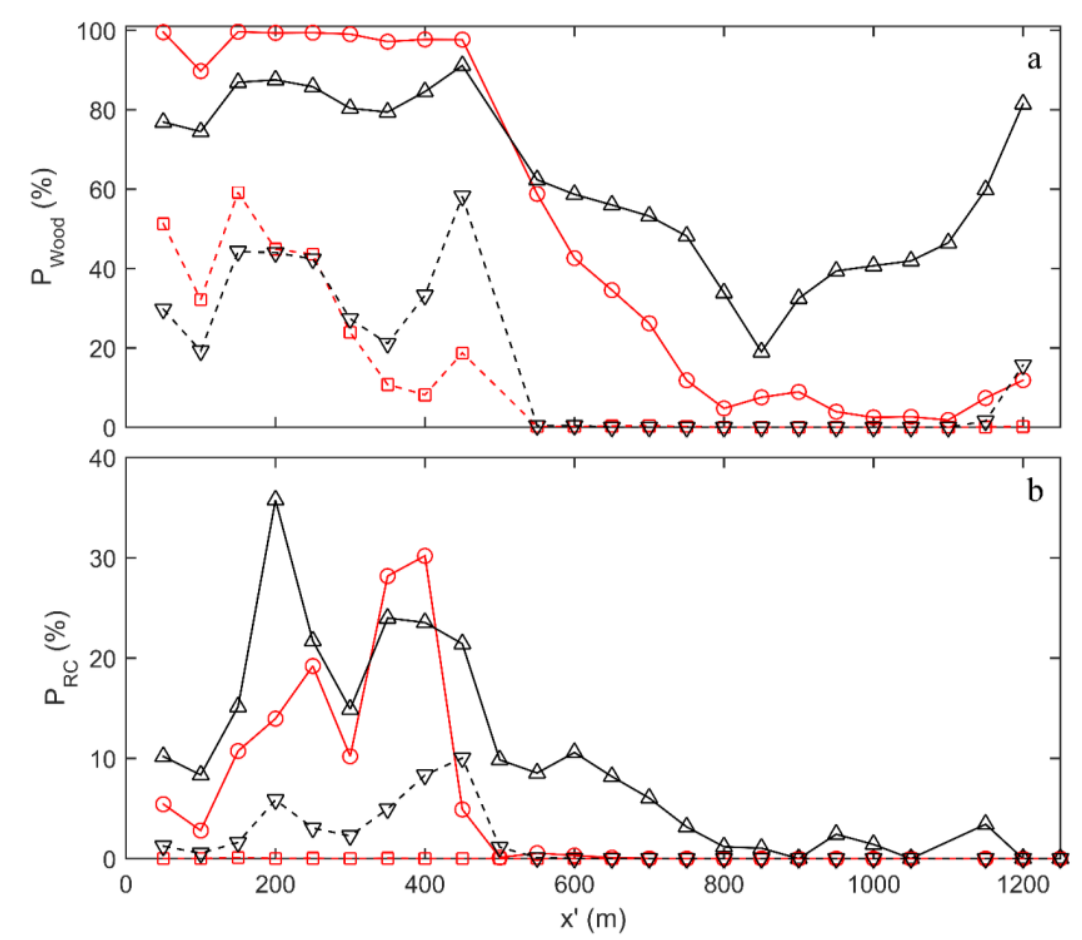

Fig. 14. Building damage sensitivity to fragility curve types for: (a) wood and (b) RC structures. Symbols: the 1,000-year (solid) and 500-year event (dashed); S2013 model (black) and FEMA model (red).

\subsection{Summary of Sensitivity Tests}

Fig. 15 summarizes the results of the five sensitivity test results shown above for: (a) Region A (wood and RC structures) and (b) Region B (wood structures only). Fig. 15a shows the mean probability of complete damage; error bars indicate the standard error with a 50\% confidence interval. Results are shown here for: (1) generation uncertainty represented by the 500-, 1,000-, and 2,500-year events; (2) uncertainty in the flow modeling represented by the variation of the friction term with $n=0.02,0.03$, and 0.04; (3) uncertainty in the floor level information; (4) uncertainty in the assigned seismic design category (SDC) using the built year as a proxy; and (5) uncertainty in fragility class used, namely the two different fragility curve models considered herein. In Fig. 15a results are shown for both wood and RC structures, although floor level and built year (SDCs) are not included for wood buildings as discussed earlier. Fig. $15 \mathrm{~b}$ shows the uncertainty in results for wood buildings only in Region B, since RC building damage was negligible in this region.

Fig. 15a shows that in Region A, the largest sensitivity for wood structures is related to the uncertainty in the tsunami generation. The probability of complete damage does not appear to be sensitive 
to the modeling of bottom friction in this case, and the fragility model shows a small sensitivity relative to that for tsunami generation. On the other hand, Fig. 15a shows that in Region A, for RC structures, all factors show relatively the same level of sensitivity. This is significant because it indicates that the uncertainty in the tsunami generation is of equal importance to the epistemic uncertainties in the inundation modeling, fragility modeling, and building classification. Similarly, Fig. 15b shows that in Region B there is an equal importance in the epistemic and aleatory uncertainties for wood structures. The impact of friction and fragility model (S2013 and FEMA 2013) on wood structures increase in Region B.
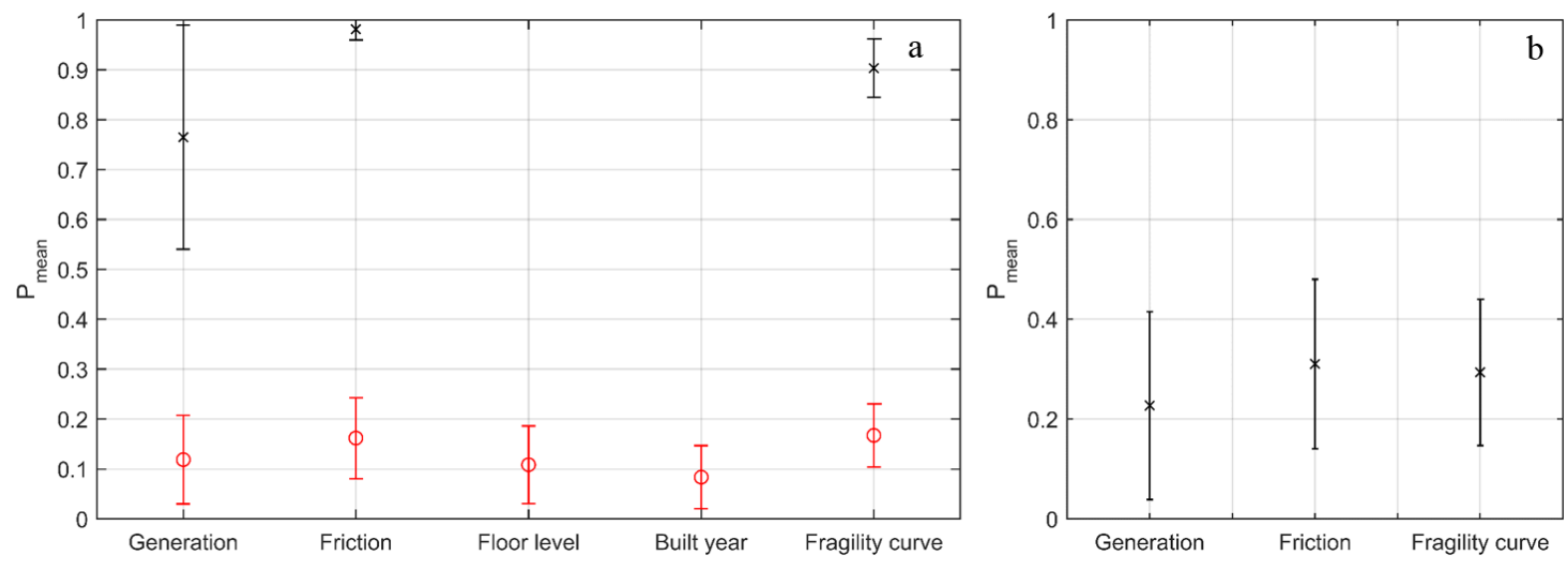

Fig. 15 Summary of building damage sensitivity tests with standard error for $50 \%$ confidence interval for (a) Region A with wood (black lines, star symbols) and RC (red lines, circles) and (b) Region B for wood only (black lines, star symbols).

\section{Discussion}

In the past decade, several empirical and analytical tsunami fragility curves were developed by different research groups. Most fragility curve models follow a similar mathematical formulation, but there are considerable differences in the curves summarized in this study. The main differences are due to: (1) each fragility curve set is developed according to a different building classification system and damage state description; (2) the building classifications and damage states are not enough to represent all of the complex structural geometries in a community (for example, the presence of openings and shapes) (3) the techniques for tsunami hazard assessment and statistical methods used to develop fragility curves are also different (Tarbotton et al. 2015). In this study, the S2013 model is used as a representative model for fragility curves that use maximum inundation depth as an IM and the FEMA model is used as a representative of fragility curves that use maximum momentum flux as an IM. 


\section{Manuscript for submission COASTAL ENGINEERING}

The numerical models used to estimate the intensities of the tsunami inundation and flow are based on bare-earth bathymetry and topography, meaning that the complex flow conditions and energy dissipation caused by structures or vegetation are not considered (PC16). In particular, the maximum momentum flux can vary significantly, depending on the details of the urban built environment such as street and building layout (e.g, Park et al., 2013). In future work, it is necessary to quantify the effects of surrounding structures, vegetation and other macro-roughness elements in numerical models for the tsunami intensity measure estimates.

Three sources were used to obtain building information, including tax lot data, Google Street View, and Rapid Visual Screening. Because of the several thousands of buildings located in Seaside, OR, this study relied primarily on the information obtained from tax lot data, which often requires validation. Perhaps more importantly, each tax lot parcel represents a single business unit rather than a particular building structure. Moreover, on large lots, the algorithms used in this study assumed that the building would be located in the geometric center of the lot. For cases where the spatial variation of the IM is low, this assumption may not be an issue. However, there can be large spatial variations in momentum flux as shown in this work. Future work could further explore this sensitivity.

The both sets of fragility curve utilized here cannot account for all possible loads on building due to the complex and transient response of buildings and also the process of the calculations of each load itself includes uncertainty. Therefore, the momentum flux based fragility curves of FEMA, 2013 developed with the assumption that the only hydrodynamic loads cause the major complete damage to the structural system rather than other type of loads. In addition, they parameterized the debris (impact and damming) and shield effects with a single coefficient, $K_{d}$ as shown in Eq. 3. There is no guide line for this coefficient yet, because of the limited studies for the practical application of debris and shield effects on damage estimation. However, it is worthy to note here that the advantage of use of the momentum flux based fragility curves is that they developed with both the flow depth and velocity which are the fundamental component to evaluate other types of loads such as buoyancy, uplifting, and impulsive forces and also scour effects on building. Therefore, the momentum flow based fragility curve is perhaps a more applicable model to reflect the complex building response during the inundation process rather than the flow depth based fragility curve. On the other hand, it may be necessary to replace fragilities curves with a fragility surface comprised of depth and velocity as independent variables (e.g., Attary et al., 2016).

The shaking and ground deformation from the earthquake will likely cause building damage before the arrival of a tsunami and its resulting damage, particularly for RC buildings. Fragility curves 36 


\section{Manuscript for submission COASTAL ENGINEERING}

developed from field survey data (e.g. S2013 model) may include some earthquake damage aspects. FEMA (2013) suggested to combine each building's damage probability of an earthquake and tsunami assuming that each event is statistically independent. In this study, the focus was placed on tsunami damage estimates, and the earthquake damage was not considered, although multi-hazard damage estimates must account for both hazards.

\section{Conclusion}

This study provides a framework for a probabilistic tsunami damage assessment (PTDA) of buildings at the scale of a small coastal city. The PTDA framework is applied to Seaside, Oregon, which is exposed to the threat of a possible future CSZ event. The PTDA framework consists of two main parts: (a) the probabilistic tsunami hazard assessment, and (b) the conditional probabilistic tsunami damage assessment.

The main contributions and conclusions of this study are:

1. The tax lot data enables classification of buildings quickly at a community scale. Google Street View and RVS can be used to verify and update the building classifications.

2. For a 1,000-year CSZ tsunami in the City of Seaside, in a region within 400 meters from the shoreline (Region A), results indicate that wood structures have a very high probability (> 80\%) of experiencing complete damage. RC structures have a lower probability of complete damage ( $40 \%)$.

3. Fragility models that are dependent of flow-depth as an intensity measure, such as the S2013 fragility model, predicted larger probabilities of complete damage for buildings near the Necanicum River and the Neawanna Creek, while the maximum momentum flux based model (FEMA model) showed a sharp decrease in the probability of complete damage as the distance from the shoreline increased.

4. For the case of wood buildings in Region A, the damage assessment results were most sensitive to the uncertainty in the tsunami generation and least sensitive to variation of bottom friction coefficients in the numerical model.

5. For the case of RC buildings in Region A, all uncertainty factors such as tsunami generation, numerical modeling, building information (floor levels and seismic design code levels) and type of fragility curve show similar sensitivity effects on damage estimation. Similarly, for the case of 
wood buildings in Region B, tsunami generation, numerical modeling, and fragility model selection were equally important for the damage assessment sensitivity.

In future work, this framework can be extended to other civil infrastructure systems (transportation, energy, communication, and water/wastewater networks), or to nearby communities. These extensions will help researchers understand the impact of a tsunami, not only on infrastructure but also on social and economic systems at a county scale. These fragilities will provide fundamental information to engineers and decision makers to implement strategies that increase the resilience of communities to future tsunami events. In addition, it is necessary to include the effects of an earthquake at CSZ, which generate seismic waves on the ground at the study site before the first tsunami wave approaches. Since our study only considers the building damage induced from tsunami inundation, accumulated damage due to ground motion and soil liquefaction may increase the total building damage. Understanding the combined earthquake and tsunami impact on buildings is one of the challenging problems of the future. 


\section{Acknowledgement}

Funding for this study was provided as part of the cooperative agreement 70NANB15H044 between the National Institute of Standards and Technology (NIST) and Colorado State University through a subaward to Oregon State University. The content expressed in this paper are the views of the authors and do not necessarily represent the opinions or views of NIST or the U.S Department of Commerce. 


\section{References}

Attary, N., van de Lindt, J., Unnikrishnan, V., Barbosa, A., and Cox, D., 2016. "Methodology for Development of Physics-Based Tsunami Fragilities." Journal of Structural Engineering, 10.1061/(ASCE)ST.1943-541X.0001715, 04016223.

Bricker, J.D., Gibson, S., Takagi, H. and Imamura, F., 2015. On the Need for Larger Manning's Roughness Coefficients in Depth-Integrated Tsunami Inundation Models. Coastal Engineering Journal, 57(02), 1550005.

Charvet, I., Suppasri, A. and Imamura, F., 2014. Empirical fragility analysis of building damage caused by the 2011 Great East Japan Tsunami in Ishinomaki City using ordinal regression, and influence of key geographical features. Stochastic Environmental Research and Risk Assessment, 28(7), $1853-1867$.

Chock, G. Y., 2016. Design for tsunami loads and effects in the ASCE 7-16 standard. Journal of Structural Engineering, 04016093.

Cornell, C.A., 1968. Engineering seismic risk analysis. Bulletin of the Seismological Society of America, 58(5), 1583-1606.

Dominey-Howes, D., Dunbar, P., Varner, J., and Papathoma-Köhle, M., 2010. Estimating probable maximum loss from a Cascadia tsunami. Natural Hazards, 53(1), 43-61.

Ellingwood, B.R., Rosowsky, D.V., Li, Y. and Kim, J.H., 2004. Fragility assessment of light-frame wood construction subjected to wind and earthquake hazards. Journal of Structural Engineering, 130(12), 1921-1930.

FEMA, 2002. Earthquake Loss Estimation Methodology, HAZUS99-MR1, Advanced Engineering Building Module, Technical and User's Manual, prepared by National Institute of Building Sciences (NIBS) for the Federal Emergency Management Agency. (Washington, D.C.: NIBS).

FEMA P-154, 2015. Rapid visual screening of buildings for potential seismic hazards: a handbook. 3rd edn, http://www.fema.gov/media-library-data/1426210695633-d9a280e72b328721

61efab26a602283b/FEMAP-154_508.pdf

FEMA, 2011. Multi-hazard Loss Estimation Methodology: Earthquake Model, HAZUS-MH MR4 Technical Manual, prepared by the National Institute of Building Sciences (NIBS) for the Federal Emergency Management Agency. (Washington, D.C.: NIBS).

FEMA P-646, 2012. Guidelines for Design of Structures for Vertical Evacuation from Tsunamis (2nd Ed.), Federal Emergency Management Agency, Washington, D.C.

FEMA, 2013. Tsunami Methodology Technical Manual, prepared by the National Institute of Building Sciences (NIBS) for the Federal Emergency Management Agency. (Washington, D.C.: NIBS). 
Fritz, H.M., Phillips, D.A., Okayasu, A., Shimozono, T., Liu, H., Mohammed, F., Skanavis, V., Synolakis, C.E. and Takahashi, T., 2012. The 2011 Japan tsunami current velocity measurements from survivor videos at Kesennuma Bay using LiDAR. Geophysical Research Letters, 39(7).

Goda, K., and Song, J., 2015. Uncertainty modeling and visualization for tsunami hazard and risk mapping: a case study for the 2011 Tohoku earthquake. Stochastic Environmental Research and Risk Assessment, 1-15.

Goda, K., Yasuda, T., Mori, N., and Mai, P. M., 2015. Variability of tsunami inundation footprints considering stochastic scenarios based on a single rupture model: Application to the 2011 Tohoku earthquake. Journal of Geophysical Research: Oceans, 120(6), 4552-4575.

Goldfinger C, Nelson CH, Morey AE, Johnson JE, Patton JR, Karabanov E., Patton, J., Gracia, E., Enkin, R., Dallimore, A., Dunhill, G., and Vallier, T., 2012. Turbidite Event History: Methods and Implications for Holocene Paleoseismicity of the Cascadia Subduction Zone U.S. Geological Survey Professional Paper 1661-F, 178 p.

González, F.I., Geist, E.L., Jaffe, B., Kânoğlu, U., Mofjeld, H., Synolakis, C.E., Titov, V.V., Arcas, D., Bellomo, D., Carlton, D. and Horning, T., 2009. Probabilistic tsunami hazard assessment at seaside, Oregon, for near-and far-field seismic sources. Journal of Geophysical Research: Oceans, 114(C11).

Hall, J. W., Dawson, R. J., Sayers, P. B., Rosu, C., Chatterton, J. B., and Deakin, R., 2003. A methodology for national-scale flood risk assessment. In Proceedings of the Institution of Civil Engineers-Water Maritime and Engineering (Vol. 156, No. 3, pp. 235-248). London: Published for the Institution of Civil Engineers by Thomas Telford Ltd., c2000-c2003.

Koshimura, S., Oie, T., Yanagisawa, H., and Imamura, F., 2009. Developing fragility functions for tsunami damage estimation using numerical model and post-tsunami data from Banda Aceh, Indonesia. Coastal Engineering Journal, 51(03), 243-273.

Raskin, J., and Wang, Y., 2016. Fifty-Year Resilience Strategies for Coastal Communities at Risk for Tsunamis. Natural Hazards Review, B4016003.

Leelawat, N., Suppasri, A., Charvet, I. and Imamura, F., 2014. Building damage from the 2011 Great East Japan tsunami: quantitative assessment of influential factors. Natural Hazards, 73(2), 449-471.

Lynett, P., Wu, T., and Liu, P., 2002. Modeling wave runup with depth-integrated equations. Coastal Engineering 46: 89-107.

Mas, E., Koshimura, S., Suppasri, A., Matsuoka, M., Matsuyama, M., Yoshii, T., ... and Imamura, F., 2012. Developing Tsunami fragility curves using remote sensing and survey data of the 2010 Chilean Tsunami in Dichato. Natural Hazards and Earth System Science, 12(8), 2689-2697.

Mimura, N., Yasuhara, K., Kawagoe, S., Yokoki, H. and Kazama, S., 2011. Damage from the Great East Japan Earthquake and Tsunami-a quick report. Mitigation and Adaptation Strategies for Global Change, 16(7), 803-818. 
Mori, N., Takahashi, T., Yasuda, T. and Yanagisawa, H., 2011. Survey of 2011 Tohoku earthquake tsunami inundation and run-up. Geophysical Research Letters, 38(7).

Mori, N., Cox, D.T., Yasuda, T. and Mase, H., 2013. Overview of the 2011 Tohoku earthquake tsunami damage and its relation to coastal protection along the Sanriku Coast. Earthquake Spectra, 29(s1), S127-S143.

MRl, HAZUS-MH, 2003. Multi-Hazard Loss Estimation Methodology: Earthquake Model. Department of Homeland Security, FEMA, Washington, DC.

Murao, O., and Nakazato, H., 2010. Vulnerability functions for buildings based on damage survey data in Sri Lanka after the 2004 Indian Ocean tsunami, in Proceedings of the 7th International Conference on Sustainable Built Environment, 13-14 December 2010, Kandy, Sri Lanka.

Naito, C., Cox, D., Yu, K., Brooker, H., 2013 Fuel Storage Container Performance During the 2011 Tohoku Japan Tsunami, Journal of Performance of Constructed Facilities, July/August, DOI: 10.1061/(ASCE)CF.1943-5509.0000339

Nistor, I., Palermo, D., Nouri, Y., Murty, T., and Saatcioglu, M., 2009. Tsunami-induced forces on structures. Handbook of coastal and ocean engineering, 261-286.

Padgett, J. E., and DesRoches, R., 2008. Methodology for the development of analytical fragility curves for retrofitted bridges. Earthquake Engineering \& Structural Dynamics, 37(8), 1157-1174.

Park, H., Cox, D. T., Lynett, P. J., Wiebe, D. M., and Shin, S., 2013. Tsunami inundation modeling in constructed environments: A physical and numerical comparison of free-surface elevation, velocity, and momentum flux. Coastal Engineering, 79, 9-21.

Park, H., Wiebe, D. M., Cox, D. T., and Cox, K., 2014. Tsunami inundation modelling: Sensitivity of velocity and momentum flux to bottom friction with application to building damage at Seaside, Oregon. Coastal Engineering Proceedings, 1(34), 1.

Park, H., and Cox, D. T., 2016. Probabilistic assessment of near-field tsunami hazards: Inundation depth, velocity, momentum flux, arrival time, and duration applied to Seaside, Oregon. Coastal Engineering, 117, 79-96.

Priest, G. R., Goldfinger, C., Wang, K., Witter, R. C., Zhang, Y., and Baptista, A. M., 2010. Confidence levels for tsunami-inundation limits in northern Oregon inferred from a 10,000-year history of great earthquakes at the Cascadia subduction zone. Natural Hazards, 54(1), 27-73.

Priest, G.R., Stimely, L.L., Wood, N.J., Madin, I.P. and Watzig, R.J., 2016. Beat-the-wave evacuation mapping for tsunami hazards in Seaside, Oregon, USA. Natural Hazards, 80(2), 1031-1056.

Reese, S., Cousins, W. J., Power, W. L., Palmer, N. G., Tejakusuma, I. G., and Nugrahadi, S., 2007. Tsunami vulnerability of buildings and people in South Java-field observations after the July 2006 Java tsunami. Natural Hazards and Earth System Science, 7(5), 573-589. 
Reese, S., Bradley, B. A., Bind, J., Smart, G., Power, W., \& Sturman, J., 2011. Empirical building fragilities from observed damage in the 2009 South Pacific tsunami. Earth-Science Reviews, 107(1), 156-173.

Raskin, Jay, and Yumei Wang., 2016. Fifty-Year Resilience Strategies for Coastal Communities at Risk for Tsunamis. Natural Hazards Review, B4016003.

Rossetto, T., Peiris, N., Pomonis, A., Wilkinson, S.M., Del Re, D., Koo, R. and Gallocher, S., 2007. The Indian Ocean tsunami of December 26, 2004: observations in Sri Lanka and Thailand. Natural Hazards, 42(1), 105-124.

Scawthorn, C., Flores, P., Blais, N., Seligson, H., Tate, E., Chang, S., Mifflin, E., Thomas, W., Murphy, J., Jones, C. and Lawrence, M., 2006. HAZUS-MH flood loss estimation methodology. II. Damage and loss assessment. Natural Hazards Review, 7(2), pp.72-81.

Suppasri, A., Koshimura, S., and Imamura, F., 2011. Developing tsunami fragility curves based on the satellite remote sensing and the numerical modeling of the 2004 Indian Ocean tsunami in Thailand. Natural Hazards and Earth System Science, 11(1), 173-189.

Suppasri, A., Mas, E., Koshimura, S., Imai, K., Harada, K. and Imamura, F., 2012. Developing tsunami fragility curves from the surveyed data of the 2011 Great East Japan tsunami in Sendai and Ishinomaki plains. Coastal Engineering Journal, 54(01), p.1250008.

Suppasri, A., Mas, E., Charvet, I., Gunasekera, R., Imai, K., Fukutani, Y., Abe, Y., Imamura, F., 2013. Building damage characteristics based on surveyed data and fragility curves of the 2011 Great East Japan tsunami. Natural Hazards, 66(2), 319-341.

Suppasri, A., Charvet, I., Imai, K. and Imamura, F., 2015. Fragility Curves Based on Data from the 2011 Tohoku-Oki Tsunami in Ishinomaki City, with Discussion of Parameters Influencing Building Damage. Earthquake Spectra, 31(2), 841-868.

Tarbotton, C., Dall'Osso, F., Dominey-Howes, D. and Goff, J., 2015. The use of empirical vulnerability functions to assess the response of buildings to tsunami impact: Comparative review and summary of best practice. Earth-Science Reviews, 142, 120-134.

Titov, V. V., Moore, C. W., Greenslade, D. J. M., Pattiaratchi, C., Badal, R., Synolakis, C. E., and Kânoğlu, U., 2011. A new tool for inundation modeling: Community Modeling Interface for Tsunamis (ComMIT). Pure and Applied Geophysics, 168(11), 2121-2131.

Valencia, N., Gardi, A., Gauraz, A., Leone, F., and Guillande, R., 2011. New tsunami damage functions developed in the framework of SCHEMA project: application to European-Mediterranean coasts. Natural Hazards and Earth System Science, 11(10), 2835-2846.

van de Lindt, J.W. and Dao, T.N., 2009. Performance-based wind engineering for wood-frame buildings. Journal of Structural Engineering, 135(2), 169-177. 
Wang, H., Mostafizi, A., Cramer, L. A., Cox, D., and Park, H., 2016. An agent-based model of a multimodal near-field tsunami evacuation: Decision-making and life safety. Transportation Research Part C: Emerging Technologies, 64, 86-100.

Wang, K., Wells, R., Mazzotti, S., Hyndman, R. D., and Sagiya, T., 2003. A revised dislocation model of interseismic deformation of the Cascadia subduction zone. Journal of Geophysical Research: Solid Earth (1978-2012), 108(B1).

Whitman, R. V., Anagnos, T., Kircher, C. A., Lagorio, H. J., Lawson, R. S., \& Schneider, P., 1997. Development of a national earthquake loss estimation methodology. Earthquake Spectra, 13(4), 643-661.

Wiebe, D. M., and Cox, D. T., 2014. Application of fragility curves to estimate building damage and economic loss at a community scale: a case study of Seaside, Oregon. Natural Hazards, 71(3), 2043-2061.

Witter, R. C., Zhang, Y. J., Wang, K., Priest, G. R., Goldfinger, C., Stimely, L., ... and Ferro, P. A., 2013. Simulated tsunami inundation for a range of Cascadia megathrust earthquake scenarios at Bandon, Oregon, USA. Geosphere, 9(6), 1783-1803.

Wood, N., 2007. Variations in city exposure and sensitivity to tsunami hazards in Oregon (No. 20075283). Geological Survey (US).

Yeh, H., 2007. Design tsunami forces for onshore structures. Journal of Disaster Research, 2(6), 531536.

Yeh, H., Sato, S., \& Tajima, Y., 2013. The 11 March 2011 East Japan earthquake and tsunami: tsunami effects on coastal infrastructure and buildings. Pure and Applied Geophysics, 170(6-8), 10191031.

Yeh, H., Barbosa, A., Ko, H., and Cawley, J., 2014. Tsunami loadings on structures: Review and analysis. Coastal Engineering Proceedings, 1(34), currents.4.

Zhang, Y. and Baptista, A.M., 2008. SELFE: a semi-implicit Eulerian-Lagrangian finite-element model for cross-scale ocean circulation. Ocean Modelling, 21(3), pp.71-96. 


\section{Nomenclature}

\begin{tabular}{lll}
\hline Symbol & Descriptions & Unit \\
\hline$B$ & Width of a building & $\mathrm{L}$ \\
$C_{d}$ & Drag coefficient & - \\
$F_{T S}$ & Lateral tsunami flow force & $\mathrm{MLT}^{-2}$ \\
$h$ & Inundation depth & $\mathrm{L}$ \\
$K_{d}$ & Coefficient for the shielding or debris impact & - \\
$M$ & Momentum flux & $\mathrm{L}^{3} \mathrm{~T}^{-2}$ \\
$M^{\prime}$ & Mean momentum flux & $\mathrm{L}^{3} \mathrm{~T}^{-2}$ \\
$n$ & Manning number & $\mathrm{TL}^{-1 / 3}$ \\
$P$ & Probability & - \\
$P_{\text {mean }}$ & Mean probability of damage & - \\
$P_{R C}$ & Probability damage of RC buildings & - \\
$P_{W o o d}$ & Probability damage of wood buildings & - \\
$x^{\prime}$ & Distance to shore-normal direction & $\mathrm{L}$ \\
$y^{\prime}$ & Distance to shore-parallel direction & $\mathrm{L}$ \\
$z$ & Ground elevation from referenced level & $\mathrm{L}$ \\
$\beta_{M}$ & Total logarithmic standard deviation for $M$ & $\mathrm{~L}^{3} \mathrm{~T}^{-2}$ \\
$\mu$ & Mean & $\mathrm{L} \mathrm{or} \mathrm{L}^{3} \mathrm{~T}^{-2}$ \\
$\mu^{\prime}$ & Lognormal mean & $\mathrm{L} \mathrm{or} \mathrm{L} \mathrm{L}^{3} \mathrm{~T}^{-2}$ \\
$\rho_{s}$ & Density of water & $\mathrm{ML}^{-3}$ \\
$\sigma$ & Standard deviation & $\mathrm{L}$ \\
$\sigma^{\prime}$ & Lognormal standard deviation & $\mathrm{L}$ \\
$\Phi$ & Standardized normal distribution function & - \\
\hline
\end{tabular}

